\title{
Task 8.2 - Subscale Catalytic Combustor Development
}

\author{
Topical Report \\ August 15, 1996
}

\section{RECEIVED \\ AUSG 181997 \\ OSTI}

Work Performed Under Contract No.: DE-AC21-93MC30246

For

U.S. Department of Energy

Office of Fossil Energy

Morgantown Energy Technology Center

P.O. Box 880

Morgantown, West Virginia 26507-0880

By

Solar Turbines, Inc.

P. O. Box 85376

San Diego, California 92186-5376

DSTRABUTON OF THIS DOCUMEN is U UTME

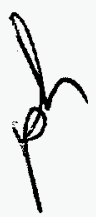




\section{Disclaimer}

This report was prepared as an account of work sponsored by an agency of the United States Government. Neither the United States Government nor any agency thereof, nor any of their employees, makes any warranty, express or implied, or assumes any legal liability or responsibility for the accuracy, completeness, or usefulness of any information, apparatus, product, or process disclosed, or represents that its use would not infringe privately owned rights. Reference herein to any specific commercial product, process, or service by trade name, trademark, manufacturer, or otherwise does not necessarily constitute or imply its endorsement, recommendation, or favoring by the United States Government or any agency thereof. The views and opinions of authors expressed herein do not necessarily state or reflect those of the United States Government or any agency thereof. 


\section{DISCLAIMER}

Portions of this document may be illegible electronic image products. Images are produced from the best available original document. 


\section{CONTENTS}

\section{Paragraph}

Page

1.0

INTRODUCTION

2.0

SUBSCALE CATALYTIC COMBUSTOR DEVELOPMENT

2

2.1 Background and Motivation

2.2 Catalyst Design

2.3 Subscale Rig Design and Testing

2.4 Sub-Scale Test Results 


\section{FIGURES}

Eigure
Schematic of Conventional Catalytic Combustion System

Schematic of Catalytica Combustion System With Lower Substrate Temperatures

Typical Catalyst Operating Window for ATS-S Operating Conditions

Schematic of Subscale Catalytic Combustor With Multi-Venturi

Premixer

Schematic of Subscale Catalytic Combustor With Constant Diameter Premixer and Fuel Injection Using Spokes

Schematic of Subscale Catalytic Combustor With Constant Diameter Premixer and Fuel Injection at Premixer Wall

Photograph of Subscale Catalytic Combustor Test Rig

Velocity Profile Measurements at Exit of Premixer

Schematic of Catalytic Combustor With Flow Straightener Upstream of the Bed and One Inch Diameter Centerbody

Premixing Measurements on Atmospheric Pressure Rig With Baseline Fuel Injectors at Low Fuel Flow Rates

Premixing Measurements on Atmospheric Pressure Rig With Baseline Fuel Injectors at High Fuel Flow Rates

Premixing Measurements on Atmospheric Pressure Rig With Optimized Fuel Injectors

Schematic of Fuel Injector Design With Extended Spokes 
FIGURES (Continued)

Eigure

Page

18

Premixing Measurements on Atmospheric Pressure Rig With Fuel Injectors Using Extended Spokes

Arrangement of Sampling Probes on Uncoated Catalyst Module

18

20

Premixing Measurements Under Rig Pressure and Ambient

Temperature With Baseline Fuel Injectors

19

Premixing Measurements Under Rig Pressure and $750^{\circ} \mathrm{F}$ With

Baseline Fuel Injectors

19

22

Premixing Measurements Under Rig Pressure and Temperature

With Fuel Injectors Using Extended Spokes

20

23

Premixing Measurements on Atmospheric Pressure Rig With

Static Mixers

Premixing Measurement Under Rig Pressure and Ambient

Temperature With Static Mixers

Premixing Measurements Under Rig Pressure and Ambient

Temperature With Static Mixers

Location of Thermocouples on Catalyst Bed Stage 1 and Stage 2

22

27

Emissions Measurements Under Steady State Operation at Solar Mars Full Load Conditions

Emissions Measurements Under Steady State Operation at ATS-S Full Load Conditions

Schematic of Reverse Flow Premixer

Premixing Measurements on Atmospheric Pressure Rig With Reverse Flow Premixer

Premixing Measurements Under Rig Pressure and Temperature With Reverse Flow Premixer

Emissions Measurements Under Steady State Operation at ATS-S Full Load Conditions With Reverse Flow Premixer 


\section{TABLES}

Table

Page

1

Typical Natural Gas Composition

8

2

Emissions Instrumentation

9

3

Summary of Early Catalyst Test Results 


\subsection{INTRODUCTION}

The Solar/DOE ATS engine program seeks to reduce engine pollutant emissions to single digit levels and low pattern factor. Program goals include the attainment of emissions (NOX, CO and UHC corrected to $15 \% \mathrm{O}_{2}$ ) below 10 ppmvd over the 50 to $100 \%$ load range, pattern factor less than 0.2 , and long term combustor component durability. Recent improvements in Solar's dry low NOx combustion technology (Rawlins, 1995) guarantee less than 25 ppmvd NOx and 50 ppmvd CO $\left(\otimes 15 \% \mathrm{O}_{2}\right)$ in field units. It is expected that with the incorporation of advanced combustion technology (e.g. variable geometry, use of ceramics in combustion liners, improved CO sensor based control systems, improved fuel-air premixing, advanced liner cooling, etc.) into present combustion systems, substantial reductions in emissions over currently guaranteed levels will be possible. However, the next generation of low emissions gas turbines may be required to incorporate catalytic combustion to guarantee the lowest possible levels of pollutant emissions with available technology.

As part of the Solar ATS Phase II program, catalytic combustion was selected as the primary combustion approach capable of attaining the emissions goals of the ATS program for medium sized industrial gas turbines. Catalytic combustion technology development in Phase II consisted of two main tasks : Task 2.8.2 involving the evaluation and demonstration of catalytic combustion technology at simulated engine conditions in a subscale rig environment, and Task 2.8.5 involving the design and evaluation of a single can full scale catalytic combustion system based on subscale results. Successful full scale rig operation will be followed by sector rig testing, and the procurement of a full set of engine hardware for an engine demonstration as part of Solar ATS Phase III program. If successful in the ATS program, catalytic combustion will be introduced in Solar's production turbines depending on market requirements and cost. This report discusses the goals of Task 2.8.2, and summarizes in a chronological manner Solar's sub-scale catalytic combustion technology development efforts as part of the ATS Phase II program. 


\subsection{SUBSCALE CATALYTIC COMBUSTOR DEVELOPMENT}

The primary goal of Task 2.8.2 was to evaluate subscale catalyst beds (approximately 4 in. diameter) at inlet temperatures and pressures representative of the ATS-S engine cycle for reactor ignition and catalyst activity, emissions, fuel-air turn-down capability, and sensitivity to combustor operating variables (The ATS-S is a 4 MW recuperated gas turbine that will be developed by Solar in Phase III of the ATS Program). Subscale catalyst beds designed and supplied by Engelhard Corporation were tested in a high pressure test rig. As part of long term ATS-S catalytic combustion system development, Solar entered into a technical collaboration with Catalytica Inc. to evaluate an altemate catalytic combustion technology for Solar ATS engines. Initial subscale work with Catalytica was funded by Solar and focused on the Solar Mars engine cycle. This effort is now concentrating on ATS-S engine conditions. This program is an integral part of Solar's ATS catalytic combustion technology development efforts, and results obtained in this program along with the test results in collaboration with Engelhard Corporation will be reported here. Solar will continue to work with both Engelhard Corporation and Catalytica Inc. in ATS Phase III to evaluate catalyst beds in single can full scale tests before a final selection of the technology appropriate for the ATS-S engine is made.

\subsection{BACKGROUND AND MOTIVATION}

The formation of oxides of nitrogen (NOx) follows one of three pathways: the thermal (Zeldovich) mechanism, the prompt (Fenimore) mechanism, and the nitrous oxide mechanism (Correa, 1992). Lean premixed combustion systems reduce flame temperatures by buming away from stoichiometric, and suppress thermal NO formation reactions which are highly temperature dependent above $1800 \mathrm{~K}$. In lean premixed combustion systems with ultra-low levels of NOx (<10 ppmv), the contribution of prompt NO is negligible, and most of the NO is formed by the nitrous oxide pathway (Nicol et al., 1995). Catalytic combustion is a lean-premixed combustion process, where a catalyst is used to initiate chemical reactions in a premixed fuel-air mixture at leaner conditions than in homogeneous gas-phase combustion. This allows stable combustion of lean fuel-air mixtures with adiabatic combustion temperatures less than $1650 \mathrm{~K}$. Thus, the contribution to NO formation due to the thermal pathway is essentially eliminated. Experimental studies in catalytic combustion have indicated that the coupling of surface chemistry with gas phase homogeneous reactions may lead to lower NO formation than corresponding lean premixed homogeneous combustion systems with the same overall equivalence ratio (e.g. Matthews and Sawyer, 1977; Dalla Betta et al., 1993). Hence, the catalytic combustion approach when implemented in a gas turbine combustion system will lead to substantial reductions in NOx emissions.

The knowledge of "flameless" combustion reactions on a catalyst surface is over 100 years old (Weinberg, 1986). Catalytically stabilized combustion was first demonstrated by Pfefferle (1975, 1986), and the potential for low pollutant emissions was later verified in other catalytic combustor tests (e.g. Anderson et al., 1975). In spite of these early findings, no gas turbine in the field today includes a catalytic combustion system. All gas turbine applications are either in the conceptual and laboratory testing stage (e.g. Dalla Betta et al., 1995) or in the rig testing stage (e.g. Beebe et al., 1995a, 1995b). Major challenges that have prevented the implementation of a catalytic combustor in an engine have been summarized by Kolaczkowski (1995). It is difficult to design a catalyst capable of igniting over a range of gas (air and fuel) inlet temperatures corresponding to the compressor discharge temperature at various engine loads. Moreover, catalyst substrate materials capable of withstanding surface temperatures close to adiabatic combustion temperatures (typically 2400 to $2500^{\circ} \mathrm{F}$ ) over long periods of catalyst operation are currently not available. The development of ceramics technology may provide substrates capable of sustaining extended periods of high temperature operation. However, the ability of ceramic substrates to withstand high thermal 
and mechanical shocks during engine startup and acceleration transients has not been demonstrated. The issue of long term durability of catalyst substrates, and high catalyst activity for continuous operation for $\mathbf{8 0 0 0}$ to $\mathbf{1 0 0 0 0}$ has not been resolved. It is unlikely that questions about durability of catalysts will be satisfactorily answered before a catalytic combustor is tested in the field.

Solar's strategy for implementing catalytic combustion in an engine must consider both materials and system design issues. For example, since catalysts with a wide range of ignition temperatures are not available, incorporation of preburners may be required to increase gas inlet temperatures at some engine operating conditions. Investigation of catalyst designs that limit substrate temperatures well below the adiabatic combustion temperature may help resolve the durability issue. While ultralean catalytic combustion is an effective NOx inhibitor, it also limits the amount of air available for cooling combustor components. Thus, the performance of the catalyst as a component of the combustion system has important implications on overall system design. The sub-scale catalytic combustion program seeks to improve Solar's technical knowledge base about catalyst design, performance and limitations. This information is critical to overall catalytic combustion system design to meet the challenges of engine start-up and acceleration, catalyst operation over a wide range of engine loads with low emissions, and long term component life and durability.

\subsection{CATALYST DESIGN}

As mentioned earlier, Solar has teamed with Engelhard Corporation and Catalytica Inc. for the design and fabrication of catalyst beds. It is important for gas turbine manufacturers to understand the catalyst design strategy as an input to the overall system design. The catalyst performance determines the design of the fuel-air preparation system, the post catalyst combustion region, liner cooling requirements, and determines combustor size, weight and cost. The catalyst designs used by both Engelhard and Catalytica depend on partial conversion of the fuel in the catalyst, and completion of heat release through homogeneous gas-phase reactions downstream of the catalyst. The Engelhard catalytic reactor is a multiple-piece bed design using a ceramic honeycomb substrate coated with catalytically active noble metals (e.g. Pd). The active catalyst material is proprietary. The Catalytica design uses a metal substrate and a Pd based catalyst. In this report, some important features of catalytic reactor design affecting other elements of the catalytic combustion system are discussed. Both Engelhard and Catalytica designs involve several common strategies. However, more information about the Catalytica technology is available in the open literature, and the following discussion is limited to some aspects of the design of Catalytica beds.

The fuel-air mixture is introduced into the catalyst at an overall equivalence ratio required to achieve the desired combustor outlet temperature. At a sufficiently high gas inlet temperature, reactions at the catalyst surface are initiated, leading to an increase in the catalyst surface temperature, and the reactions are essentially diffusion limited. Limited information about the kinetics of the surface reactions are available due to the proprietary nature of the catalysts. The gas temperature in the catalyst bed increases due to heat and mass transfer from the hot catalyst surface. If the gas temperature is sufficiently high, homogeneous combustion within the catalyst is initiated, leading to gas temperatures close to adiabatic combustion temperatures corresponding to the global equivalence ratio. A schematic of the design of a conventional catalytic combustor allowing homogeneous combustion within the catalyst bed is shown in Figure 1 (from Dalla Betta et al., 1993). At these high bed temperatures, problems of thermal sintering of support surface area, sintering and vaporization of active catalyst components (e.g. Pd) and thermal shock fracturing of ceramic substrates could occur (Dalla Betta et al., 1993). This is one of the major limitations of a conventional catalytic combustion system. 


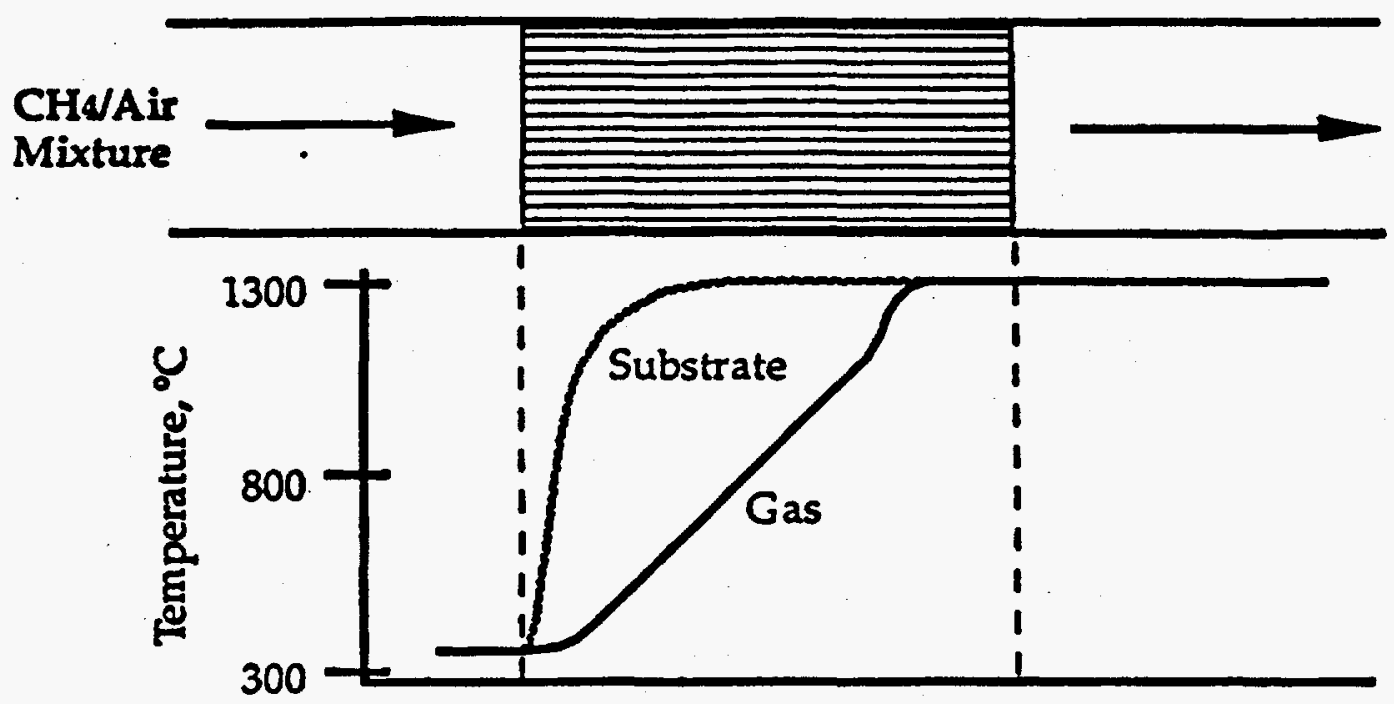

Figure 1. Schematic of Conventional Catalytic Combustion System (from Dalla Betta et al., 1993)

Catalytica's approach relies on heat release due to catalyst surface reactions and heat transfer from the hot catalyst substrate to increase the gas (fuel + air) temperature in the catalyst bed. The walls of the catalyst substrate are maintained at relatively low temperatures, and combustion of the partially combusted fuel-air mixture is completed in a homogeneous combustion zone downstream of the catalyst. The obvious advantage of this strategy is the substantially lower substrate temperature, which allows higher catalyst activity in the initial stage (where the gas temperatures are low), and a lower catalyst activity in the later stages since a higher gas temperature is provided by reactions in the inlet stage. A schematic of the Catalytica catalytic combustion design is shown in Figure 2 (from Dalla Betta et al., 1993).

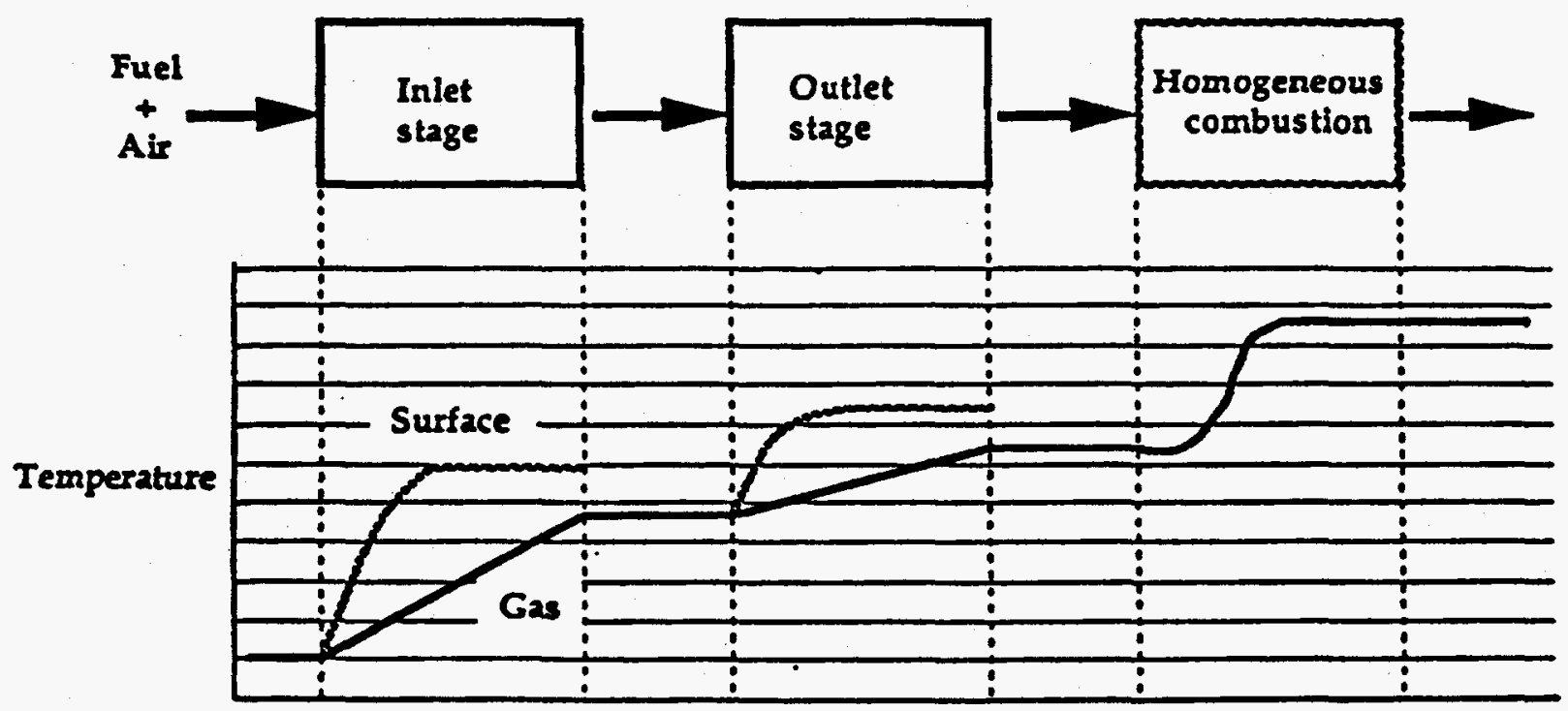

Figure 2. Schematic of Catalytica Catalytic Combustion System With Lower Substrate Temperatures (from Dalla Betta et al., 1993) 
Catalyst bed design is based on an available catalyst operating window, a typical example of which is shown in Figure 3 for the ATS-S engine cycle. The catalyst ignition temperature is approximately $700^{\circ} \mathrm{F}$, and is relatively independent of the fuel-air ratio. For the recuperated ATS-S cycle, the combustor inlet temperature is higher than the catalyst ignition temperature for loads greater than $50 \%$ of full load, and engine operation in the 50 to $100 \%$ load range would not require the use of a pre-burner. The catalyst operating window is defined by two considerations: the left portion of the operating window is fixed by the adiabatic flame temperature corresponding to the global equivalence ratio for an available residence time required for rapid $C O$ reduction ( $<10 \mathrm{ppmv}$ ), while the right portion of the window is determined by the maximum allowable substrate temperature for long term durability of the substrate and the catalyst coating. The region between these limits and the catalyst ignition temperature (shown as the shaded portion in Figure 3 ) is the operating window for the catalyst. At $100 \%$ load, the operating window is fairly large. The operating window reduces at lower engine loads, and low emissions may be possible up to $70 \%$ load without air staging.

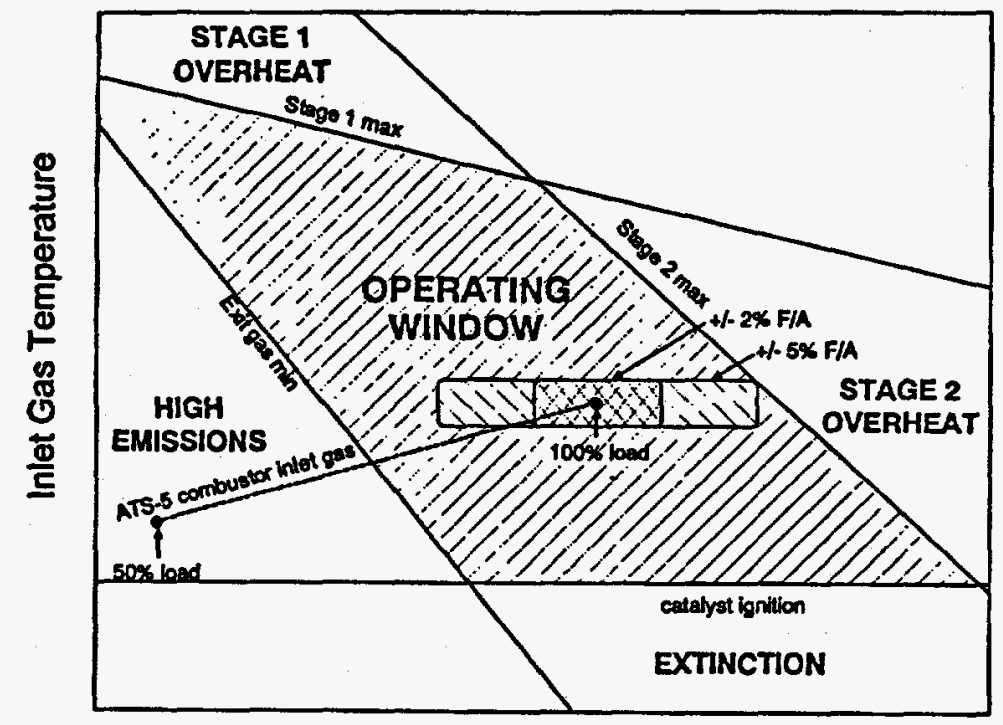

Adiabatic Combustion Temperature

Figure 3. Typical Catalyst Operating Window for ATS-S Operating Conditions
The effect of the degree of fuel-air premixing on the operating window of the catalyst is also shown in Figure 3. At full load conditions, a $10 \%$ peak to peak variation in the fuel-air ratio spans almost the entire operating window, thereby limiting the operational flexibility of the system. However, with improved premixing (e.g., $4 \%$ peak to peak variation), the smaller variation in the adiabatic combustion temperature allows a wider turndown range. Thus, the importance of substantial improvements in fuel-air premixing required in a catalytic combustion system over current lean premixed combustors cannot be over-emphasized. Operation below $70 \%$ load to achieve ultralow emissions down to $50 \%$ load, and

tolerate reasonable levels of spatial and temporal fuel-air unmixedness will require the incorporation of variable geometry design for air staging.

Based on the above information, the operation of the catalytic reactor requires a fuel preparation system capable of achieving homogeneous fuel-air mixtures, while keeping the residence time in the premixer short to prevent autoignition, and avoiding regions of separated flow to prevent flashback. Operation of the catalyst bed over a wide load range (50 to $100 \%$ ) requires variable geometry design. Moreover, even with the incorporation of variable geometry, and achievement of high levels of fuel-air premixing, operation of the catalytic combustion system will require improved control over combustor operating variables to avoid high $\mathrm{CO}$ emissions or catalyst damage due to overheating of the catalyst substrate.

\subsection{SUBSCALE RIG DESIGN AND TESTING}

A subscale catalytic combustor test rig was used to evaluate different catalyst bed designs at various inlet temperatures and pressures. A schematic of the rig used during the early tests is shown in inlet 
temperatures and pressures. The rig consists of a preheat combustor, fuel-air premixer, catalyst bed, and a post catalyst combustor. The catalyst bed is enclosed in a catalyst can which can accommodate a bed 5 inches in diameter, with a 4 inch diameter flow path. The preheat combustor incorporates a lean-premixed fuel injector, and is used to provide the required catalyst inlet temperature. The prebumer is uncoupled from the fuel-air premixer, and is located in the air supply pipe more than 15 diameters upstream of the premixer inlet.

Several premixer configurations were evaluated for their ability to provide uniform fuel-air profiles at the inlet to the bed. Three of these designs are shown in Figures 4 through 6 . These designs incorporate a multi-venturi with multi-point fuel injection, a constant diameter duct with multi-point fuel injection through tubes, and a constant diameter duct with fuel injection at multiple points on the duct wall, respectively. Plexiglas models of some of the premixer sections were fabricated, and flow visualization tests using a smoke generator were performed to check the premixer designs for flow separation and recirculation. Models were tested by flowing air using a downstream blower at ambient temperature and pressure, and injecting smoke at varying axial and radial locations through a hypodermic sized tube. Based on these qualitative results, the multi-venturi design was selected for the combustion tests. This premixer, shown in Figure 4, includes six venturis around a central venturi, and follows the general principles of a design developed by Tacina (1977). At the mouth of each venturi is a fuel delivery tube with four fuel orifices near the tip. A small angle diffuser $\left(<7^{\circ}\right)$ is used to reduce the gas flow velocity at the inlet to the bed.

The post catalyst combustor is an adiabatic volume where homogeneous gas-phase reactions are completed. Tests were conducted with and without ceramic flame stabilizer bars located downstream of the catalyst bed. Located within the post catalyst combustor is an auxiliary fuel injector which is used during startup, before the catalyst bed is ignited. A torch ignitor is also mounted in the post catalyst section in order to light-off the auxiliary fuel injector. Due to test rig size limitations, there is no dilution region at the end of the post catalyst combustor section to reduce gas temperatures to turbine inlet requirements.

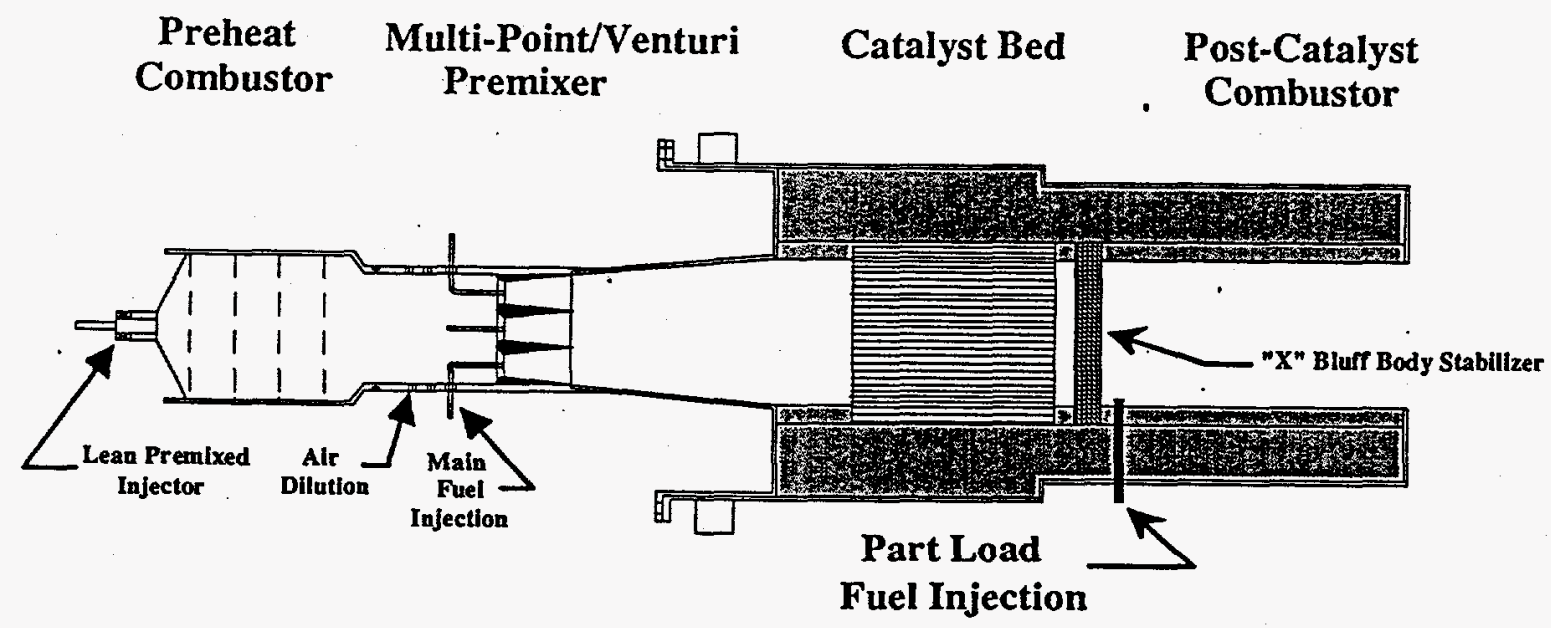

Figure 4. Schematic of Subscale Catalytic Combustor With Multi-Venturl Premixer 

Preheat
Combustor
Premixer
Catalyst Bed
Post-Catalyst
Combustor

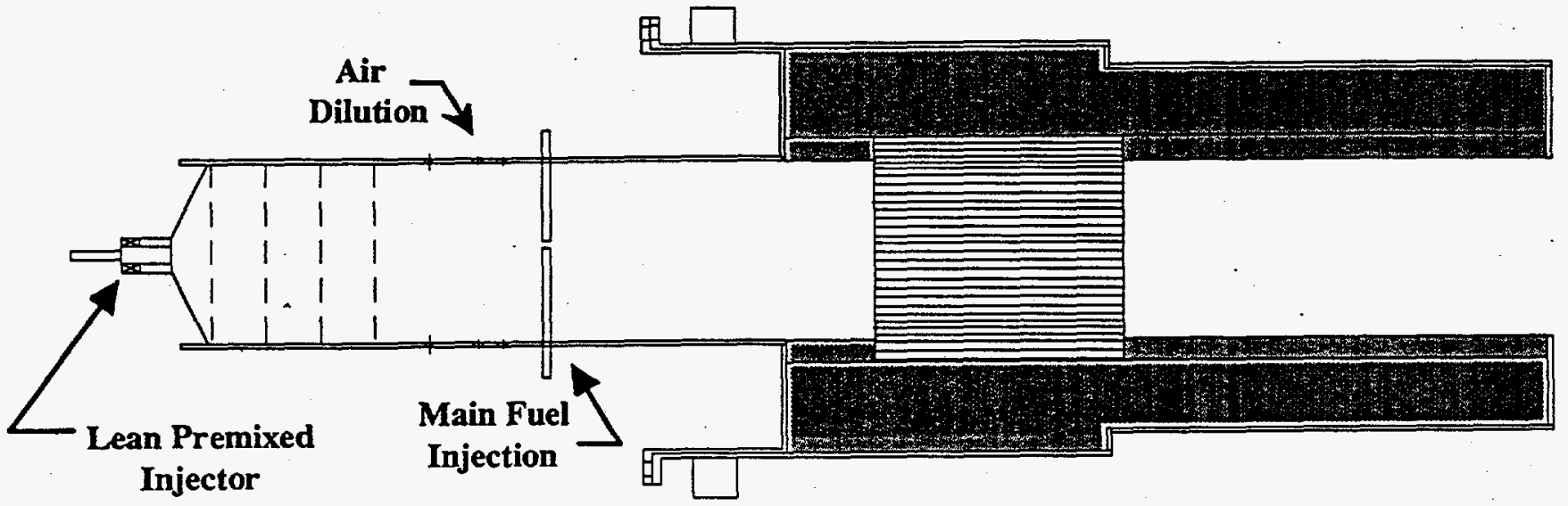

Figure 5. Schematic of Subscale Catalytic Combustor With Constant Diameter Premixer and Fuel Injection Using Spokes
Preheat
Combustor
Premixer
Catalyst Bed
Post-Catalyst
Combustor

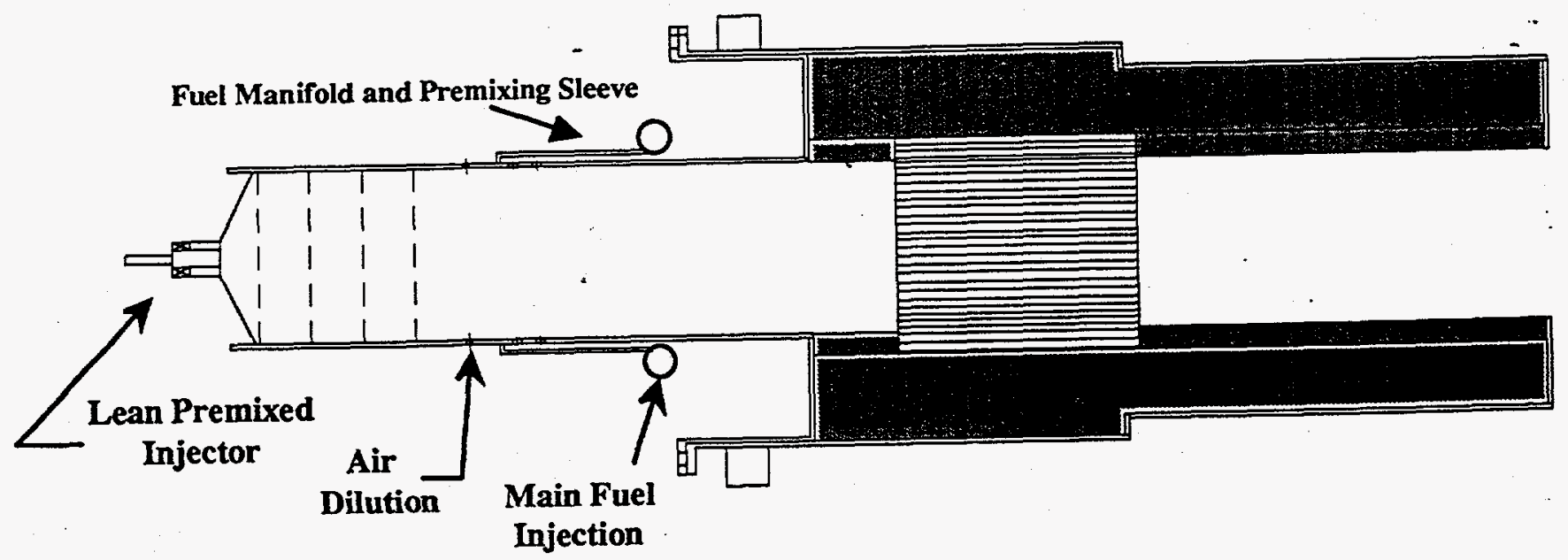

Figure 6. Schematic of Subscale Catalytic Combustor With Constant Dlameter Premixer and Fuel Injection at Premixer Wall

The combustor test rig is shown in Figure 7. Pre-heated combustion air enters the test section after being metered with an ASME sharp-edged orifice. Within the combustor housing, the air flow is initially in a reverse flow direction around the outside of the combustor liner. This reverse flow configuration simulates the flow pattern in a multiple, canted can, gas turbine combustion system. The canted burner geometry may be required to provide a high degree of flexibility in integrating an advanced catalytic combustor into an existing engine design. Combustor exhaust gases flow through a water-cooled diagnostic section and a water quench before exiting to the atmosphere. Combustor air flow rate and rig pressure are controlled using a pressure regulating valve upstream 


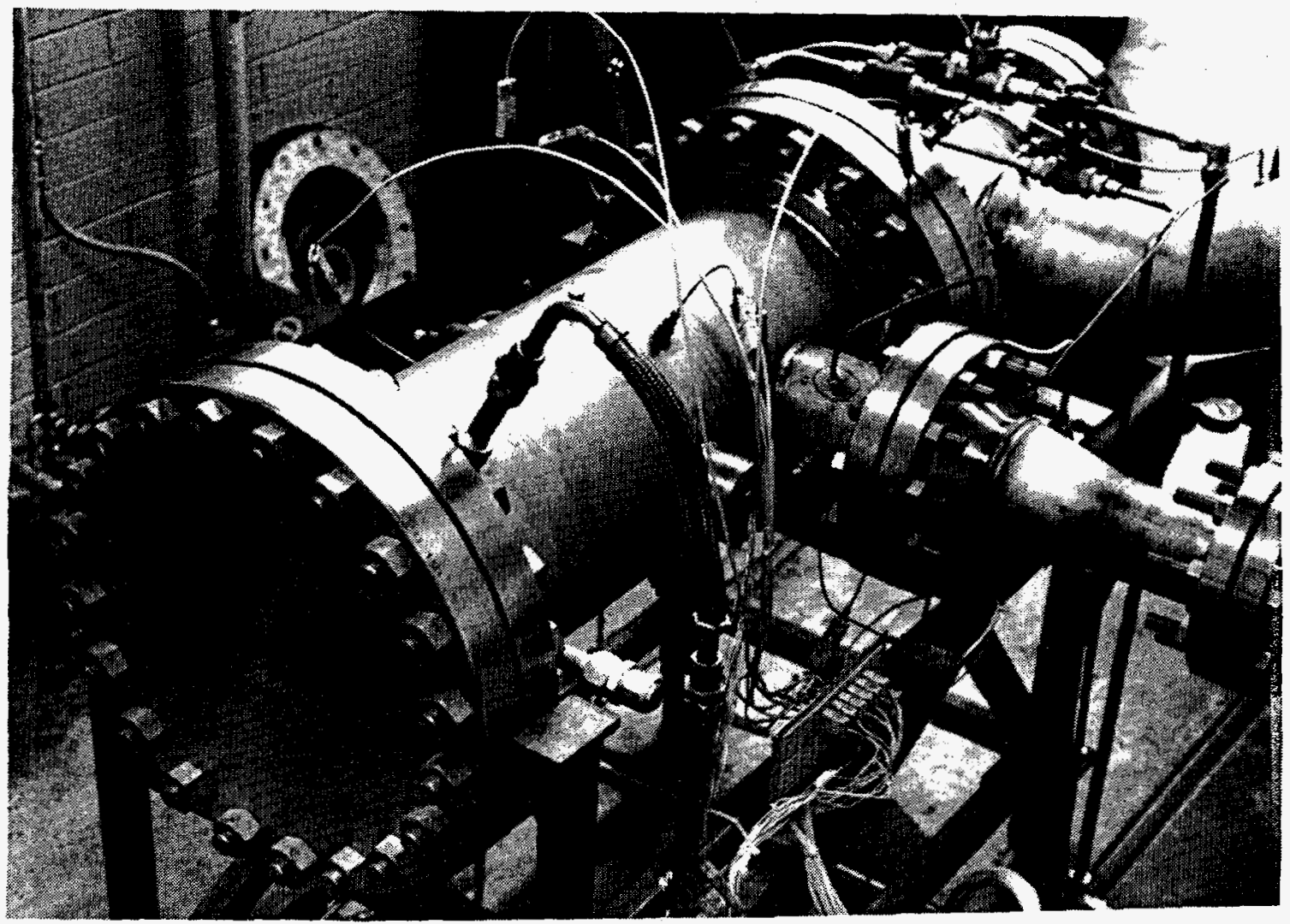

Figure 7. Photograph of Subscale Catalytic Combustor Test Rig

of the test rig and a back-pressure butterfly valve downstream of the rig. The test rig includes a small quartz window that allows visual monitoring of the catalyst exit plane.

Natural gas is delivered to the test rig from a boost compressor and metered with turbine flow meters. Typical composition of the natural gas used in the combustion tests is shown in Table 1. Main fuel flows to a manifold inside the combustor casing, where it is distributed to the seven venturi fuel tubes. Equal flow to each of the injectors is achieved by the four metering orifices in each of the fuel delivery tubes. The effective area of the fuel tubes are matched to $\pm 1.5 \%$ on a cold flow bench prior to testing. Prebumer and auxiliary burner fuel flow rates are metered by separate needle valves.

Table 1. Typical Natural Gas Composition

\begin{tabular}{|l|r|}
\hline Solar Fuel Gas Composition & Mol \% \\
\hline Methane & 92.79 \\
Ethane & 4.16 \\
Propane & 0.84 \\
Buane & 0.18 \\
Pentane & 0.04 \\
Hexane & 0.04 \\
Oxygen & 0.00 \\
Nitrogen & 1.51 \\
Carbon dioxide & 0.44 \\
\hline
\end{tabular}


Exhaust gas species concentrations are measured at the combustor exit plane using samples withdrawn from the rig by two water cooled emissions probes. Each probe spans a rig diameter, and contains a series of orifices to provide an area averaged sample. Gas samples flow to the emissions instrumentation through a heated tube to prevent hydrocarbon condensation. Table 2 lists the emissions equipment used in the present tests.

Table 2. Emissions Instrumentation

\begin{tabular}{|l|l|}
\hline \multicolumn{1}{|c|}{ Constituent } & \multicolumn{1}{|c|}{ Instrument } \\
\hline $\mathrm{NOx}$ & Beckman Model 951A NO/NOx Analyzer \\
\hline $\mathrm{CO}$ & Beckman Model 867 Infrared Analyzer \\
\hline $\mathrm{CO}_{2}$ & Rosemount Model 880 Analyzer \\
\hline $\mathrm{O}_{2}$ & Beckman Model 775 Oxygen Analyzer \\
\hline Hydrocarbons & Beckman Model 402 Hydrocarbon Analyzer \\
\hline
\end{tabular}

The test facility is instrumented to measure air and fuel flow rates, temperatures and pressures. Combustor fuel-air ratio is measured and compared to calculations based on exhaust species measurements using carbon and oxygen balance. Further data are acquired only if agreement within $5 \%$ between metered fuel-air ratio and calculations based on exhaust measurements is obtained.

The premixer performance is characterized through measurements of fuel concentrations and gas temperatures at the inlet to the catalyst bed. Initial mixing measurements were made at seven points directly upstream of the catalyst bed. Some of the premixing measurements were limited to approximately one-quarter of design point ( $1 \%$ fuel by volume, against $4 \%$ at the highest fuel-air ratio) because of the range of the hydrocarbon analyzer. Design objectives of the premixer were to provide a maximum fuel concentration variation of $\pm 5 \%$ and a maximum temperature variation of $\pm 14^{\circ} \mathrm{C}\left( \pm 25^{\circ} \mathrm{F}\right)$. Based on seven point measurements, the multiple venturi design with the diffuser section had a measured fuel variation of $\pm 1.25 \%$ and a temperature profile variation of $\pm 12^{\circ} \mathrm{C}$ $\left( \pm 22^{\circ} \mathrm{F}\right)$.

A typical test of the subscale catalytic combustor includes rig and emissions equipment warm-up, preheat combustor ignition, part load combustor light-off, and combustor performance testing. Once air is preheated to the desired operating temperature, the preheat and part load combustors are ignited with torches. After stable flames are achieved, the torch is extinguished. At this point, main fuel is started to the catalyst bed and part load fuel is reduced to maintain a constant combustor outlet temperature and pressure loss. Once the catalyst is fully ignited, part load fuel is stopped. Operational variables are then adjusted to the required conditions.

Once at the desired test point, the burner is allowed to reach a thermally stable operating condition before data are recorded. Typically, at least ten minutes are allowed for the system to reach thermal equilibrium. During this stabilization period, the catalyst exit plane is visually inspected and exhaust emissions levels are monitored. When stable operation is achieved, test data are recorded by an automated data acquisition system. 


\subsection{SUB-SCALE TEST RESULTS}

Preliminary test results with Engelhard catalyst beds are summarized in Table 3. As the table indicates, testing with these beds was primarily directed towards improving catalyst bed activity to maintain stable catalytic combustion. Stable catalytic combustion is achieved when the auxiliary burner downstream of the bed can be extinguished, and combustion is maintained. Under some test conditions, heat release in the premixing section was observed. At the higher inlet temperatures $\left(>1000^{\circ} \mathrm{F}\right)$, the catalyst inlet face velocity was maintained above $50 \mathrm{ft} / \mathrm{s}$ in order to reduce the possibility of flame propagation into the premixing duct. The initial bed design (denoted as Design A) consisted of four pieces, with an overall length of 5 inches. The temperature rise across the bed was low $\left(-100^{\circ} \mathrm{F}\right)$ and stable catalytic combustion was not achieved. In order to increase bed activity, a new catalyst design was used for piece 1 in a subsequent test (Test 4). Once again, the temperature rise across the bed was low $\left(150\right.$ to $\left.250^{\circ} \mathrm{F}\right)$, and stable catalytic combustion was not achieved. For the next test (Test 5), the preheat burner was used to provide bed inlet temperatures higher than $1100^{\circ} \mathrm{F}$, corresponding to ATS full load conditions. The existing test facility is capable of providing inlet temperatures $>1100^{\circ} \mathrm{F}$ at higher air flow rates without the use of the preburner. However, at the air flow rates used in the subscale combustion tests, the heat losses in the piping system are significant, and the preburner is needed to obtain the higher inlet temperatures. $A$ significant temperature rise was measured in Test $5\left(-500^{\circ} \mathrm{F}\right)$ due to improved bed activity at the higher inlet temperatures, and stable catalytic combustion was achieved without the auxiliary burner. The bed design was changed in order to increase the bed activity (denoted as Design B) for Test 6 , and a longer bed (6.5 in.) was used. Tests were conducted at a rig pressure of 115 psig, and at inlet temperatures between 800 and $1120^{\circ} \mathrm{F}$. Once again, the temperature rise across the bed was low, and stable combustion was not maintained. In the following test (Test 7), the activity of the first catalyst piece was increased, and stable catalytic combustion was sustained over a period of 30 minutes. Most of the measured Nox was generated in the preburner, and the increase in NOX

Table 3. Summary of Early Catalyst Test Results

\begin{tabular}{|c|c|c|c|}
\hline $\begin{array}{l}\text { Test } \\
\text { No. }\end{array}$ & Set-Up & Results & Comments \\
\hline 1 to 3 & $\begin{array}{l}\text { Bed design A ( } 4 \text { pc, } 5.0 \text { in. long). } \\
\text { Face velocity } 60 \text { fps, } 115 \text { psig, } 800 \text { to } \\
960^{\circ} \mathrm{F} \text { inlet, no preheat combustor }\end{array}$ & $\begin{array}{l}\text { Temperature rise across bed } \\
\text { below } 100^{\circ} \mathrm{F} \text {. Stable catalytic } \\
\text { combustion not achieved. }\end{array}$ & Low bed activity. \\
\hline 4 & $\begin{array}{l}\text { Bed design A, new piece 1. } 60 \mathrm{fps} \text {, } \\
775 \text { to } 980^{\circ} \mathrm{F} \text { inlet, } 4 \text { vol\%, } 118 \mathrm{psig} \text {, } \\
\text { no preheat combustor. }\end{array}$ & $\begin{array}{l}\text { Temperature rise across bed of } \\
50 \text { to } 250^{\circ} \mathrm{F} \text {. Stable catalytic } \\
\text { combustion not achieved. }\end{array}$ & $\begin{array}{l}\text { Low bed activity, } \\
\text { improved with different } \\
\text { first piece. }\end{array}$ \\
\hline 5 & $\begin{array}{l}\text { Same bed and operating conditions as } \\
\text { Test } 4 \text {. Preheat combustor operated } \\
\text { to elevate inlet temperature from } 900 \\
\text { to } 1120^{\circ} \mathrm{F} \text {. }\end{array}$ & $\begin{array}{l}\text { Temperature rise across bed of } \\
500^{\circ} \mathrm{F} \text {. Stable catalytic } \\
\text { combustion achieved without } \\
\text { auxiliary burner. }\end{array}$ & $\begin{array}{l}\text { Increased activity with } \\
\text { inlet temperature } \\
\text { increase. Catalytic com- } \\
\text { bustion not very stable. } \\
\text { Bed activity still low. }\end{array}$ \\
\hline 6 & $\begin{array}{l}\text { Bed design B (5 piece, } 6.5 \mathrm{in} \text {.). } 60 \mathrm{fps} \text {, } \\
115 \mathrm{psig}, 4 \text { vol\%, } 800 \text { to } 1120^{\circ} \mathrm{F} \text { inlet. } \\
\text { With and without preheat combustor. }\end{array}$ & $\begin{array}{l}\text { Temperature rise of } 225^{\circ} \mathrm{F} \text {. } \\
\text { Stable catalytic combustion not } \\
\text { maintained. }\end{array}$ & $\begin{array}{l}\text { Increased bed length did } \\
\text { not increase activity. }\end{array}$ \\
\hline 7 and 8 & $\begin{array}{l}\text { Bed design B, new first piece. } 60 \mathrm{fps} \text {, } \\
115 \text { psig, } 3.5 \text { to } 4 \text { vol\%, } 900 \text { to } \\
1025^{\circ} \mathrm{F} \text {, with preheat combustor. }\end{array}$ & $\begin{array}{l}\text { Temperature rise of } 300 \text { to } \\
400^{\circ} \mathrm{F} \text {. Stable catalytic com- } \\
\text { bustion maintained for } 30 \mathrm{~min} \text {. } \\
\text { High } \mathrm{CO} \text { and UHC emissions. } \\
\text { Catalyst bed cooler in center. }\end{array}$ & $\begin{array}{l}\text { Bed activity improved. } \\
\text { Cool catalyst center } \\
\text { indicates lower fuel } \\
\text { concentration in center. }\end{array}$ \\
\hline
\end{tabular}


emissions due to catalyst operation was consistently less than 3 ppmv. High levels of CO and UHC were measured (> $1000 \mathrm{ppmv} @ 15 \% \mathrm{O}_{2}$ ), and indicated non-uniform fuel-air mixing. Visual observations through the quartz window indicated that the catalyst bed appeared to operate with a relatively cooler region near the center of the bed.

In order to explain the observed cooler central portion of the catalyst bed in spite of satisfactory fuelair premixing (based on 7 probe measurements), a five-hole pitot probe was used to characterize the radial velocity profile at the exit of the premixer. Velocity measurements under ambient conditions are plotted against radial position in Figure 8 . On this plot, 2 in. corresponds to the centerline of the flow. The baseline configuration used in earlier tests is shown as "Position $A$ " in Figure 8 , and shows a $44 \%$ peak to average variation in the velocity profile. In order to approach a goal of $10 \%$ peak to average variation, three modifications were made to the premixer. The first configuration changes the baseline by replacing the diffuser ( 3 inch diameter to 4 in. diameter) with a constant 3 inch diameter premixing duct from the venturi to the catalyst bed (shown as " 3 in. Diameter Flow Path" in Figure 8). The second configuration, labeled "Center Venturi Premixer Blocked", has a one inch diameter rod mounted along the centerline from the venturi outlet to the exit of the catalyst bed. This rod completely blocks the center venturi. The final configuration is an extension of the second configuration, except that a 1.5 inch thick flow straightener is inserted upstream of the catalyst bed. A sketch of this test arrangement is shown in Figure 9. All the above modifications provided a flatter velocity profile, but the configuration shown in Figure 9 provided the most uniform velocity distribution, with a $11 \%$ peak to average variation. This configuration was chosen for the next catalyst bed test. Prior to the combustion tests, fuel-air premixing measurements were made using six fixed probes and the fuel tubes were optimized to obtain a $6.7 \%$ peak to peak variation in the fuel concentration.

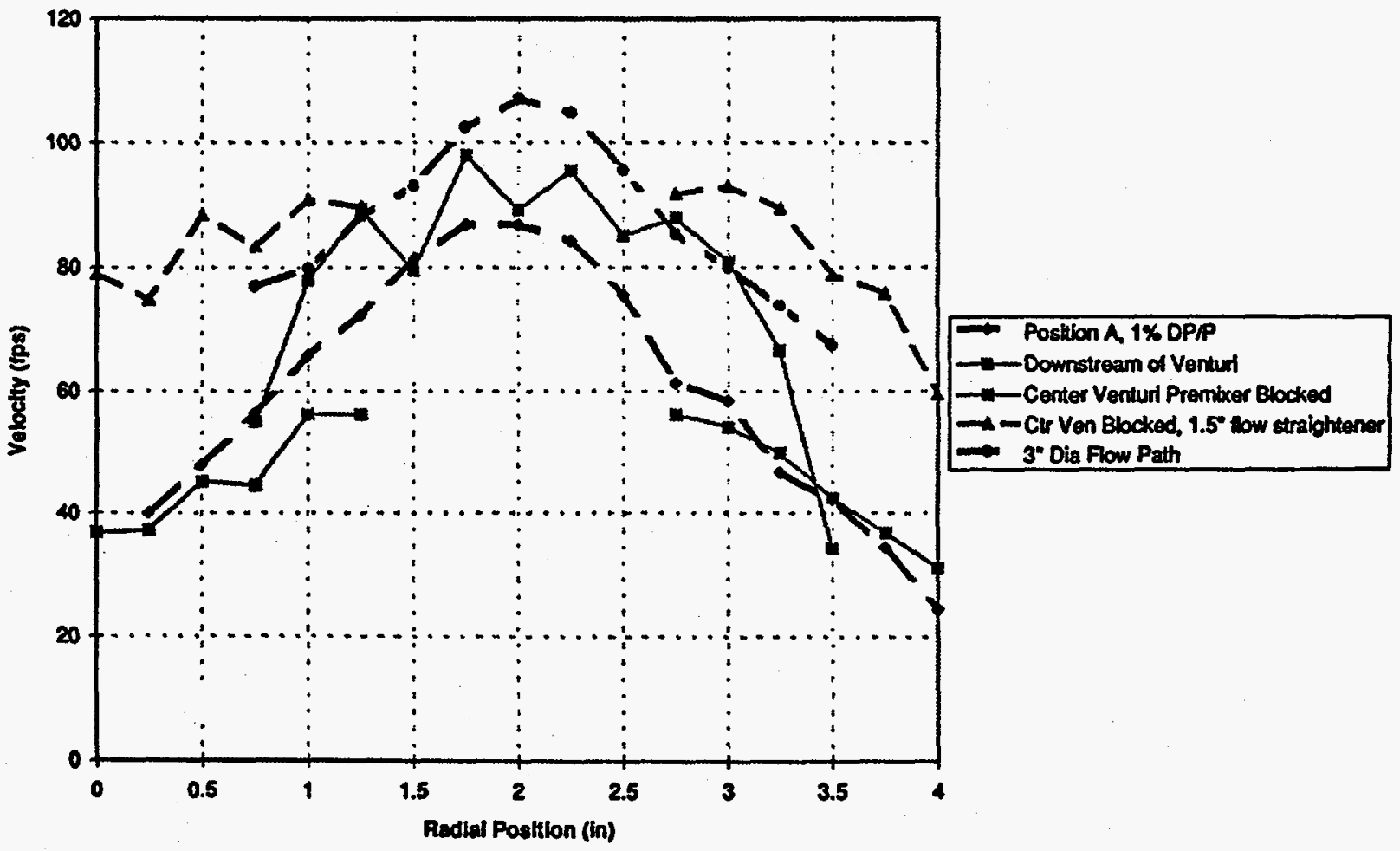

Figure 8. Velocity Profile Measurements at Exit of Premixer 


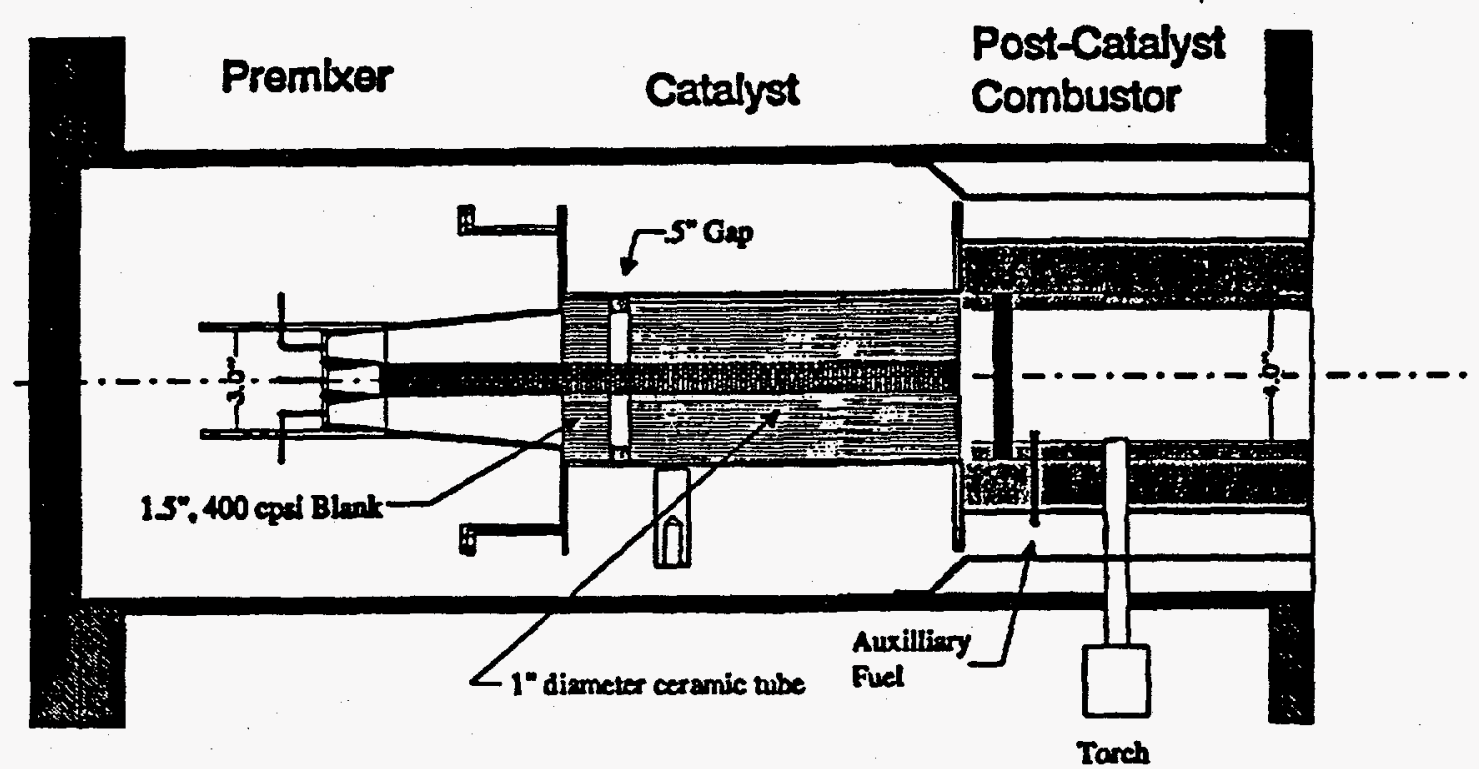

Figure 9. Schematic of Catalytic Combustor With Flow Straightener Upstream of the Bed and One Inch Diameter Centerbody

A series of combustion tests were conducted using this test configuration. The length of the catalyst bed (supplied by Engelhard) was increased to 10.5 inches (7 pieces) in order to obtain a higher fuel conversion, and higher temperature rise across the bed. Stable catalytic combustion was achieved for over two hours without any auxiliary fuel burning downstream of the catalyst bed at a rig pressure of $120 \mathrm{psig}$. The system operated in a stable manner over a range of inlet temperatures from $770^{\circ} \mathrm{F}$ to $900^{\circ} \mathrm{F}$ and a variation in fuel-air ratio from 3.7 to $4 \%$ by volume. Measured NOx emissions were consistently below 3 ppmv (corrected to $15 \% \mathrm{O}_{2}$ ). CO and UHC emissions, however, were as high as 1000 ppmv of CO and $250 \mathrm{ppmv}$ of UHC (@ 15\% $\mathrm{O}_{2}$ ). Some of the "cleaner" emissions measurements are shown in Figure 10, where the CO levels are about 100 ppmv and HC emissions

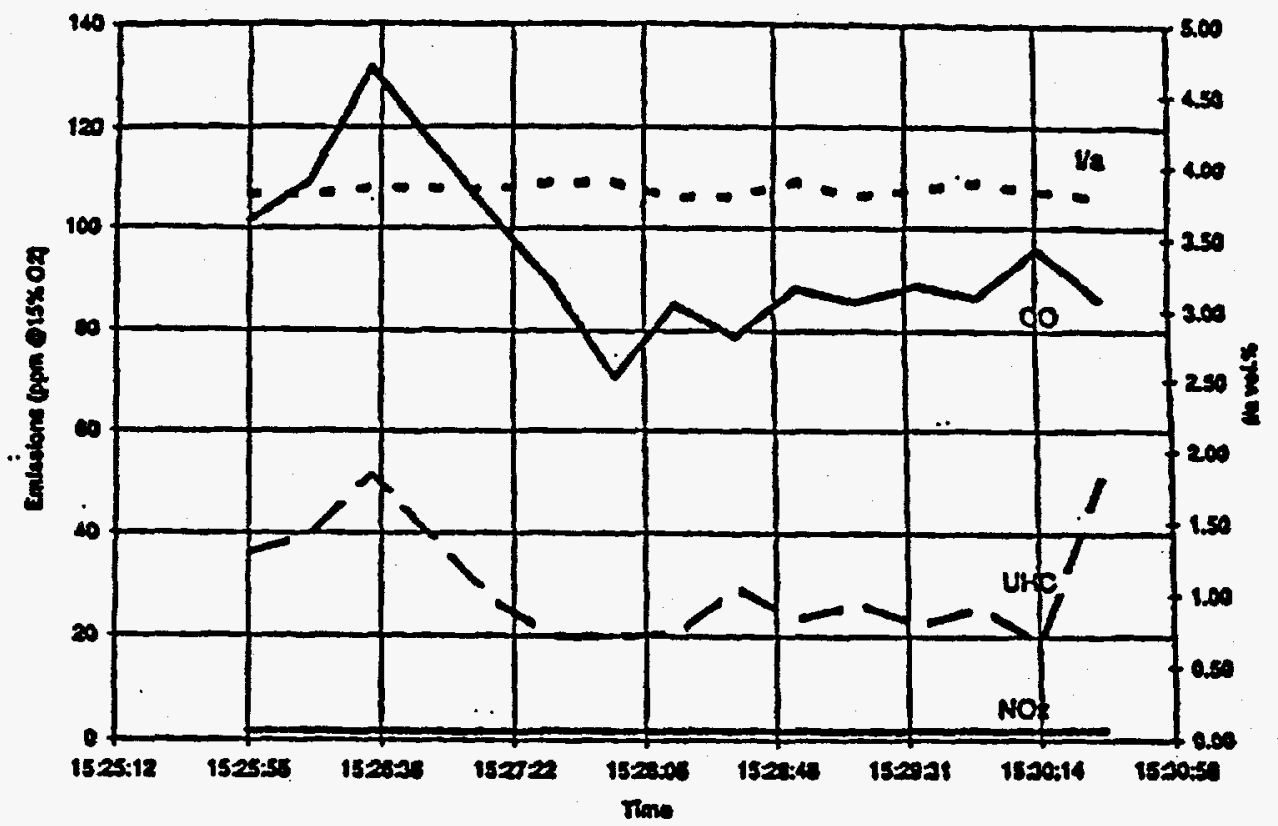

Figure 10. Emissions Measurements With Engelhard Catalyst Bed With Configuration Shown In Figure 9. 
below 60 ppmv. On post test inspection, the catalyst bed was found to be in good condition, except for a one inch diameter circle where the bed was deformed, and some of the material was missing. The cause of the substrate failure was a hot spot (bed temperature $>2500^{\circ} \mathrm{F}$ ) that developed during testing at the higher fuel-air ratios. A part of the reason for the high $\mathrm{CO}$ and UHC emissions was attributed to insufficient residence time downstream of the bed, and the post catalyst flow path was increased from a diameter of 4 inches to 6 inches for subsequent tests, leading to a factor of 2.25 increase in the residence time.

The catalyst bed was instrumented with 14 thermocouples in order to obtain the gas temperature at the center and near the wall of the catalyst container at the exit of each catalyst stage. Temperature measurements at the centerline and the wall (normalized by the mean temperature at that catalyst stage) for two axial locations (catalyst stages 3 and 4) are shown in Figures 11 and 12. The data show a significant difference between wall and centerline temperatures, and also large temperature fluctuations under essentially steady state catalyst operation. The velocity profile measurements ( $11 \%$ peak to average variation) and the fuel concentration measurements $(6.7 \%$ peak to peak variation) do not provide an adequate explanation for the measured temperature non-uniformity across the bed and the damage to a sector of the bed. It was decided that fuel-air profile measurements based on six fixed probes was not an accurate indicator of the levels of fuel-air premixing. An existing atmospheric pressure premixing test rig was modified to perform detailed fuel-air concentration measurements at the exit of the premixer. A schematic of the modified premixing rig is shown in Figure 13. The premixer module is enclosed in a 12 in. pipe, and velocity measurements are performed at the exit of the premixer (as shown in Figure 13) with a five-hole pitot probe to match nominal premixer residence times under ambient conditions to nominal residence times under test conditions. Mean fuel concentration measurements were conducted with a sixprobe sampling rake that spans the premixing duct. The sampling rake can be rotated in increments of $20^{\circ}$. Fuel concentrations as a function of radial and angular location for the premixer configuration used in the previous test are shown in Figures 14 and 15 for two fuel flow rates. At the lower fuel

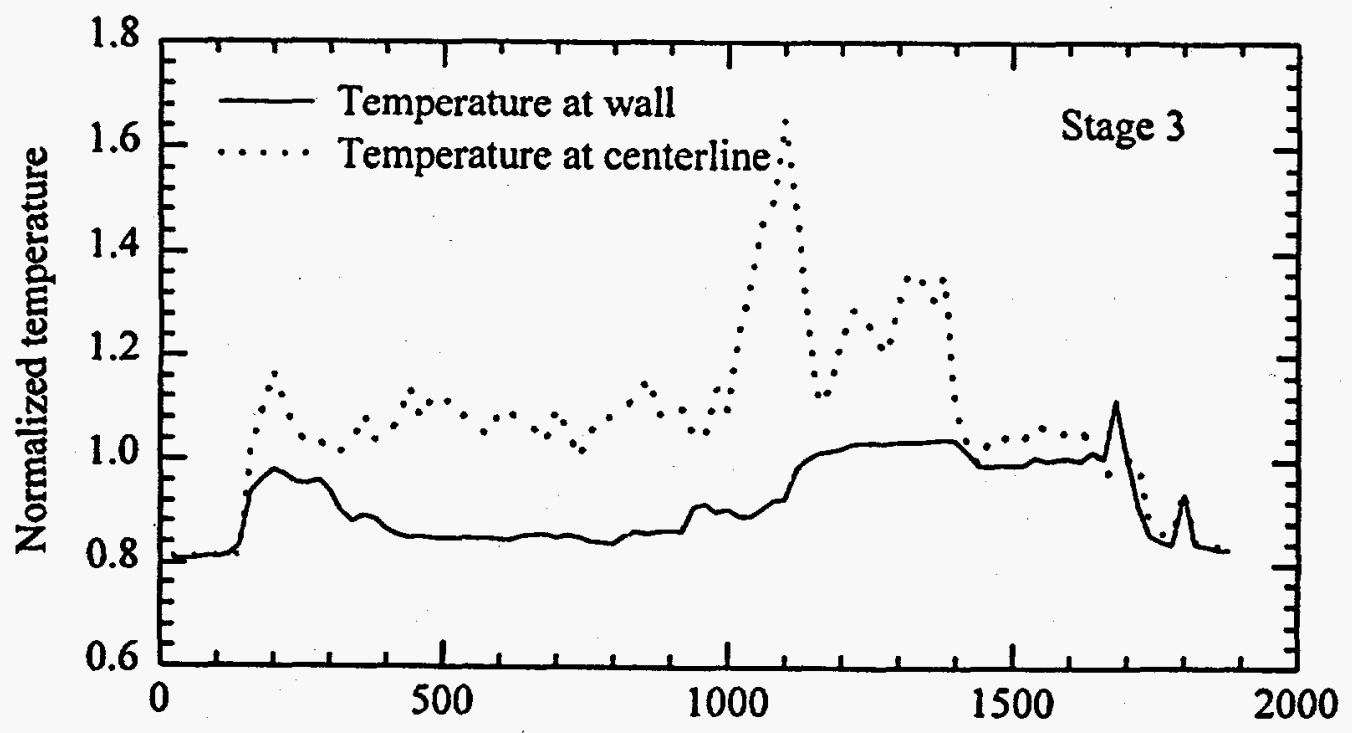

Time (s)

Figure 11. Measured Temperatures at Wall and Centerline of Catalyst at Stage 3 Exit 


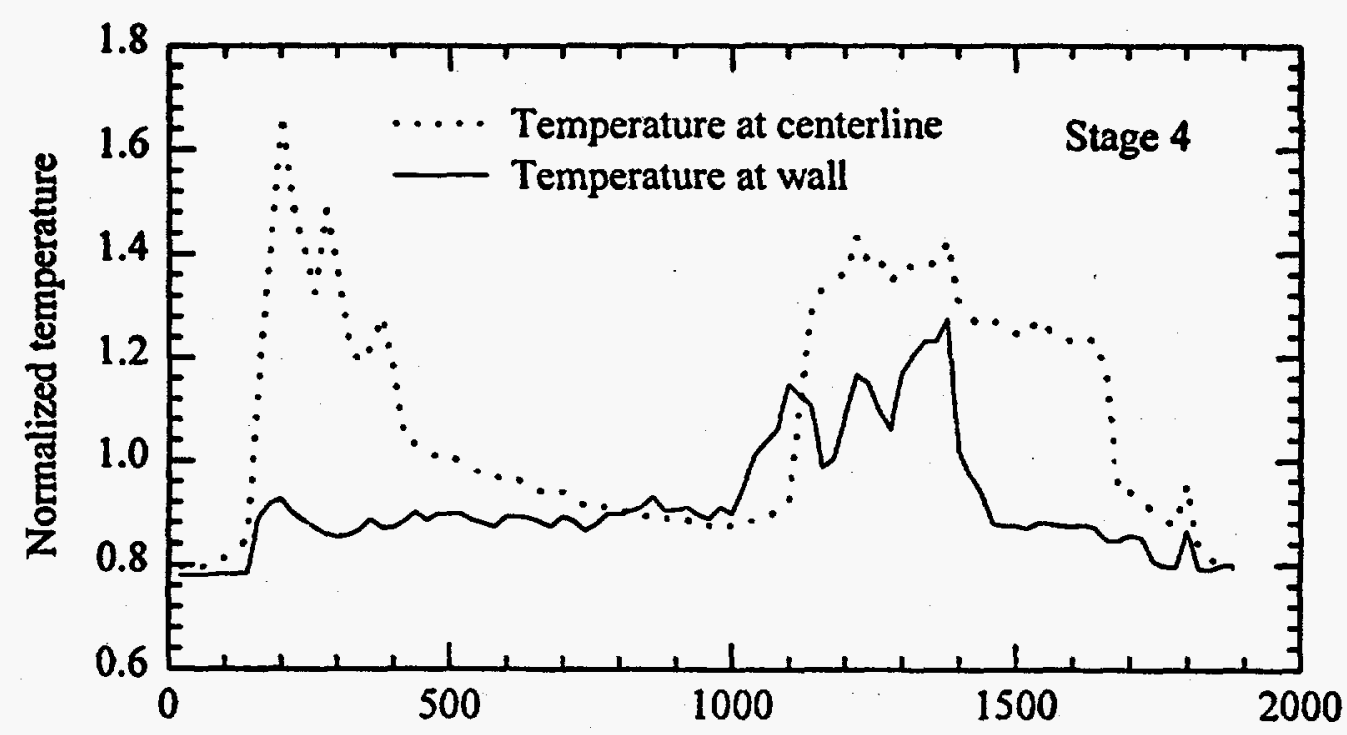

Time (s)

Figure 12. Measured Temperatures at Wall and Centerline of Catalyst at Stage 4 Exit

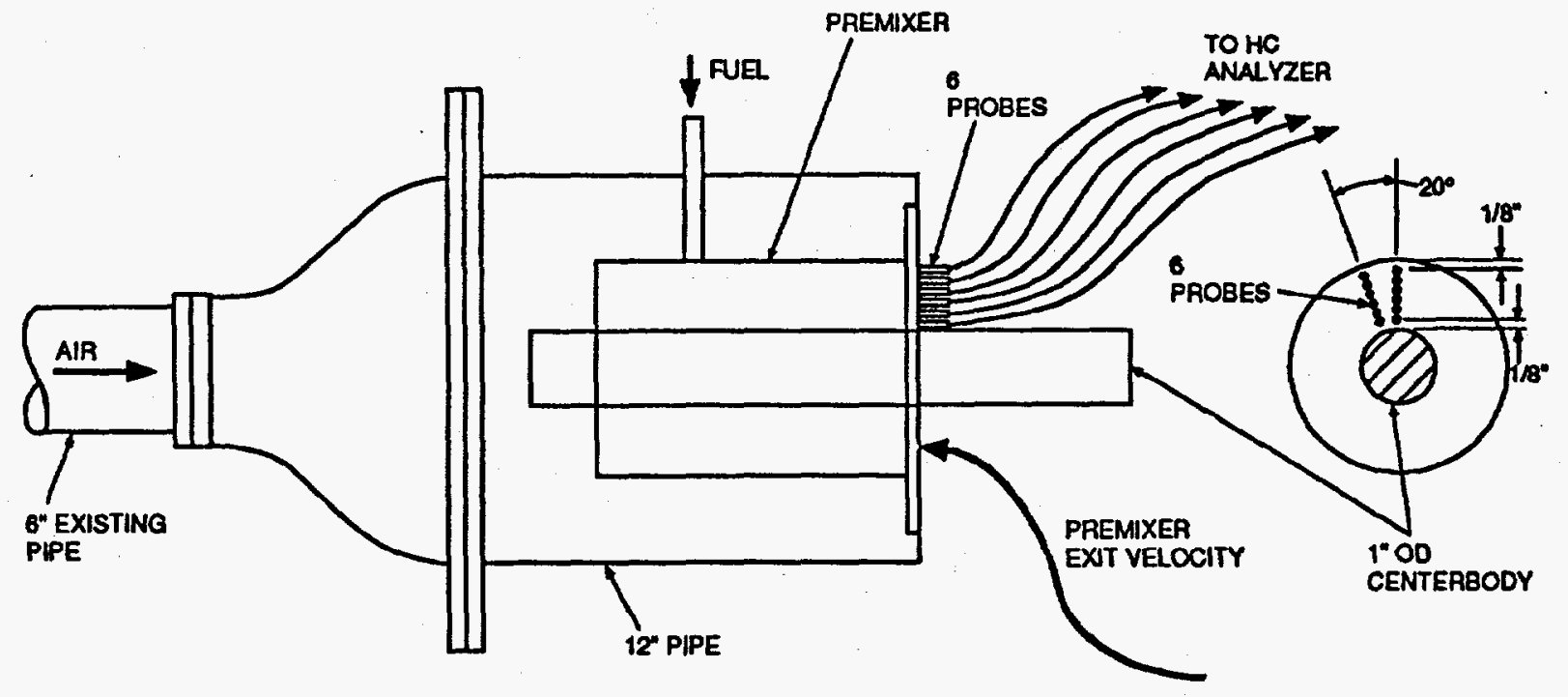

Figure 13. Schematic of Atmospheric Pressure Premixing Rig

flow rates, high radial and circumferential non-uniformity are observed. The peak to peak fuel concentration variation of approximately $40 \%$ (Fig. 14) could explain the local overheating and damage to a sector of the catalyst bed, and the high $\mathrm{CO}$ and UHC emissions. At higher fuel flow rates, the fuel jet momentum increases, and the radial non-uniformity in fuel concentration decreases (Fig. 15). However, the circumferential non-homogeneity is still outside the specification for the catalyst.

Based on the results shown in Figure 15, an optimization of the fuel tube hole size and orientation was performed. Premixing data for this configuration are shown in Figure 16 and show improved radial and circumferential fuel uniformity (peak to peak variation 15\%). This approach was not pursued due to the unacceptable increase in the fuel pressure drop across the fuel injector orifice, 


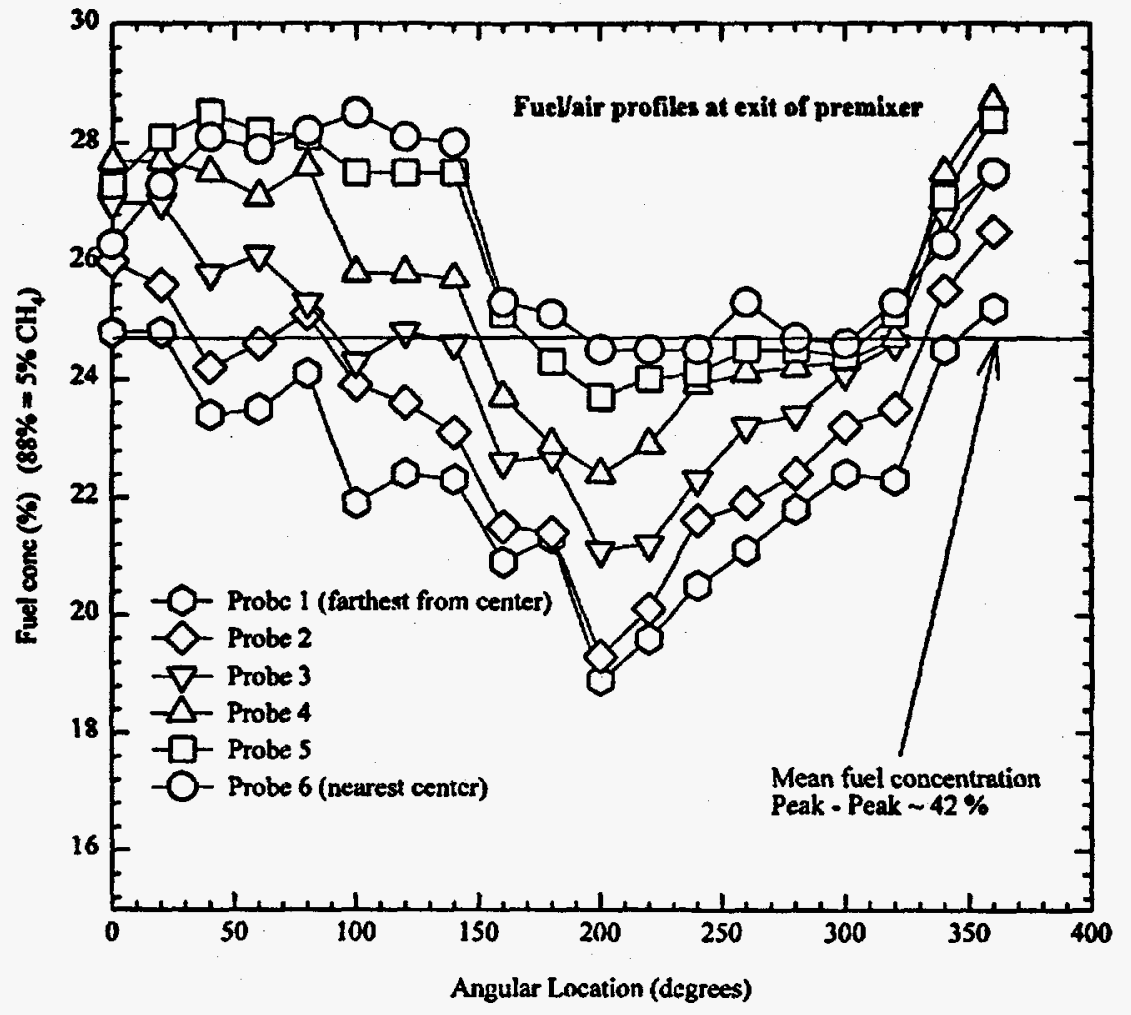

Figure 14. Premixing Measurements on Atmospheric Pressure Rig With Baseline Fuel Injectors at Low Fuel Flow Rates

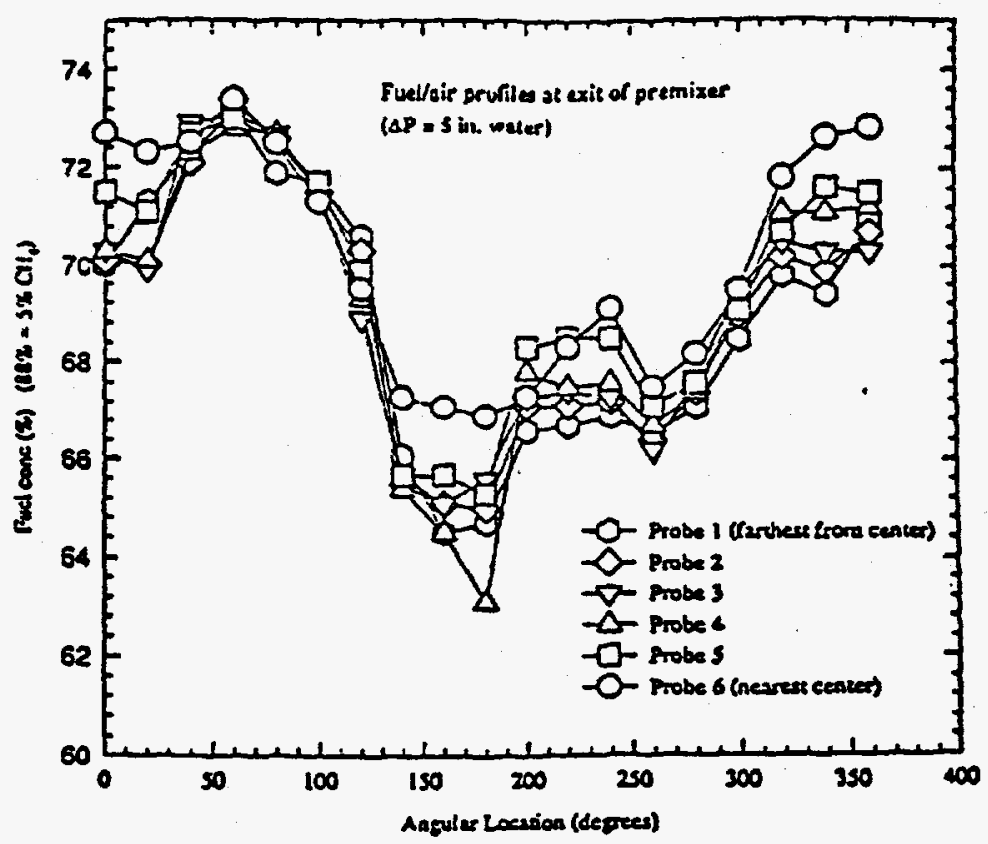

Figure 15. Premixing Measurements on Atmospheric Pressure Rig with Baseline Fuel Injectors at High Fuel Flow Rates 


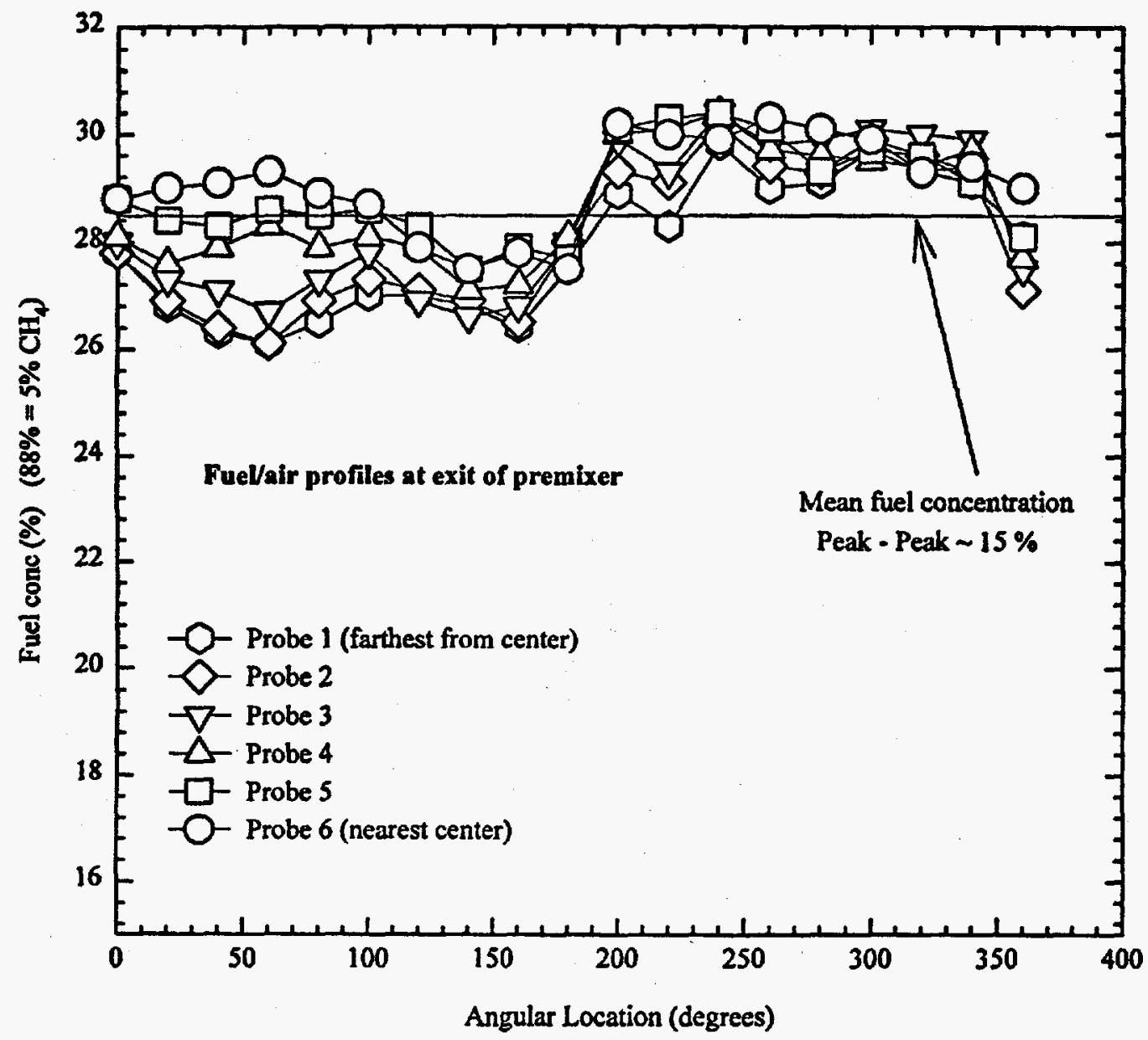

Figure 16. Premixing Measurements on Atmospheric Pressure Rig With Optimized Fuel Injectors

and concems about the quality of premixing at lower fuel flow rates. In order to address the problem of varying fuel jet penetration at different fuel flow rates, a new fuel spoke design shown in Figure 17 was introduced. Fuel injectors with extension tubes to achieve better radial penetration independent of fuel flow rates were fabricated. Premixing measurements on the atmospheric pressure rig with the new injectors are shown in Figure 18. Except for a sector at the premixer exit $\left(20\right.$ to $80^{\circ}$ ), where fuel concentrations were significantly lower, generally uniform radial and angular profiles were measured. The cause for the non-uniformity in the 20 to $80^{\circ}$ sector was determined to be a blockage in the fuel orifice located in that sector, and was subsequently corrected.

A catalyst bed supplied by Catalytica was tested under Mars baseline operating conditions with the new injectors. Desired bed activity was achieved at low inlet temperatures $\left(-800^{\circ} \mathrm{F}\right)$ and lean fuelair ratios. However, local overheating of a portion of the catalyst sector caused substrate damage and prevented successful completion of the test. Once again, the results are not consistent with the fuel-air premixing measurements obtained on the atmospheric pressure rig prior to the test.

In order to resolve the fuel-air premixing issue, and to determine if it was the cause for prior catalyst damage and high $\mathrm{CO}$ and UHC emissions, it was decided to perform the fuel concentration 


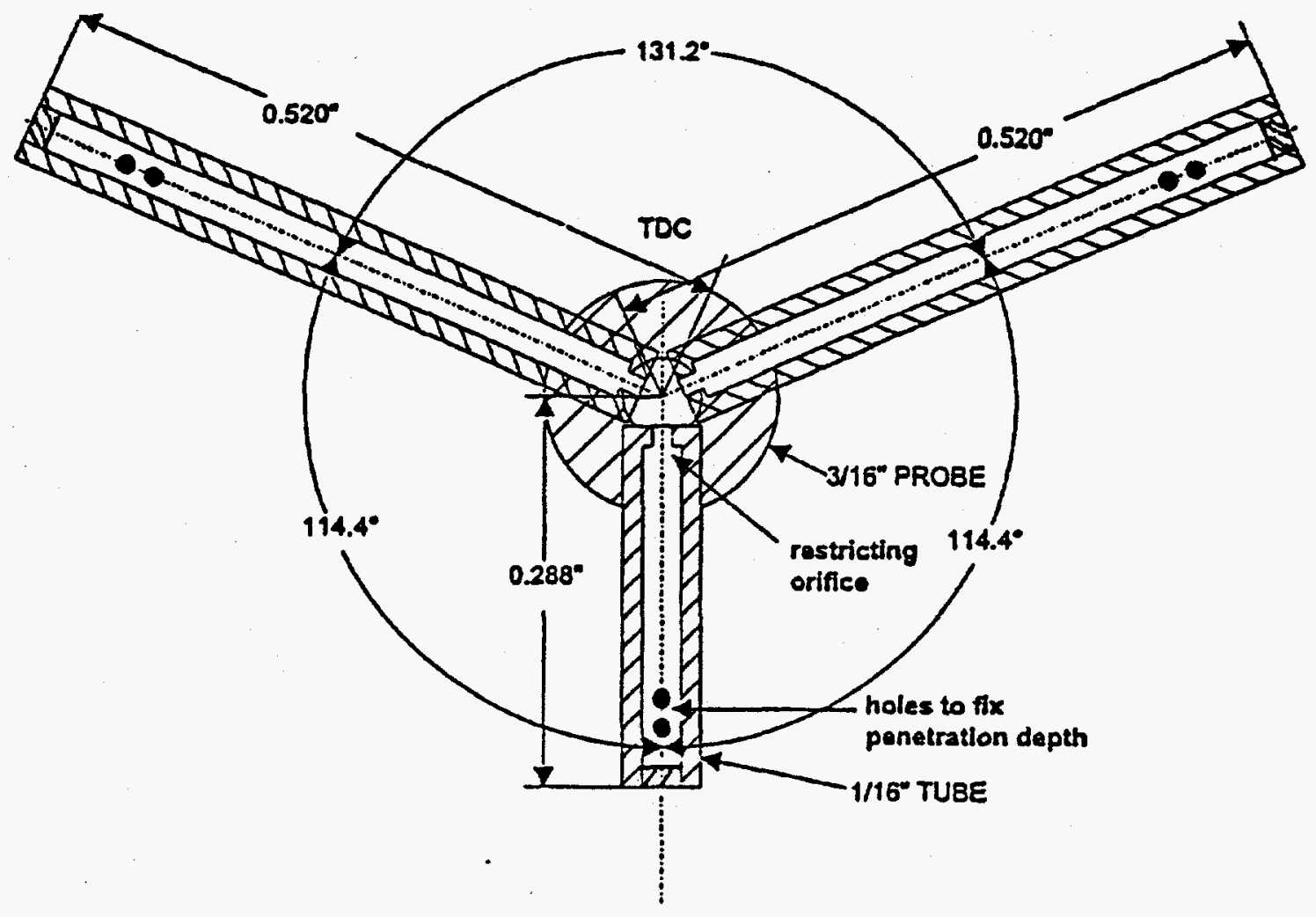

Figure 17. Schematic of Fuel Injector Design With Extended Spokes

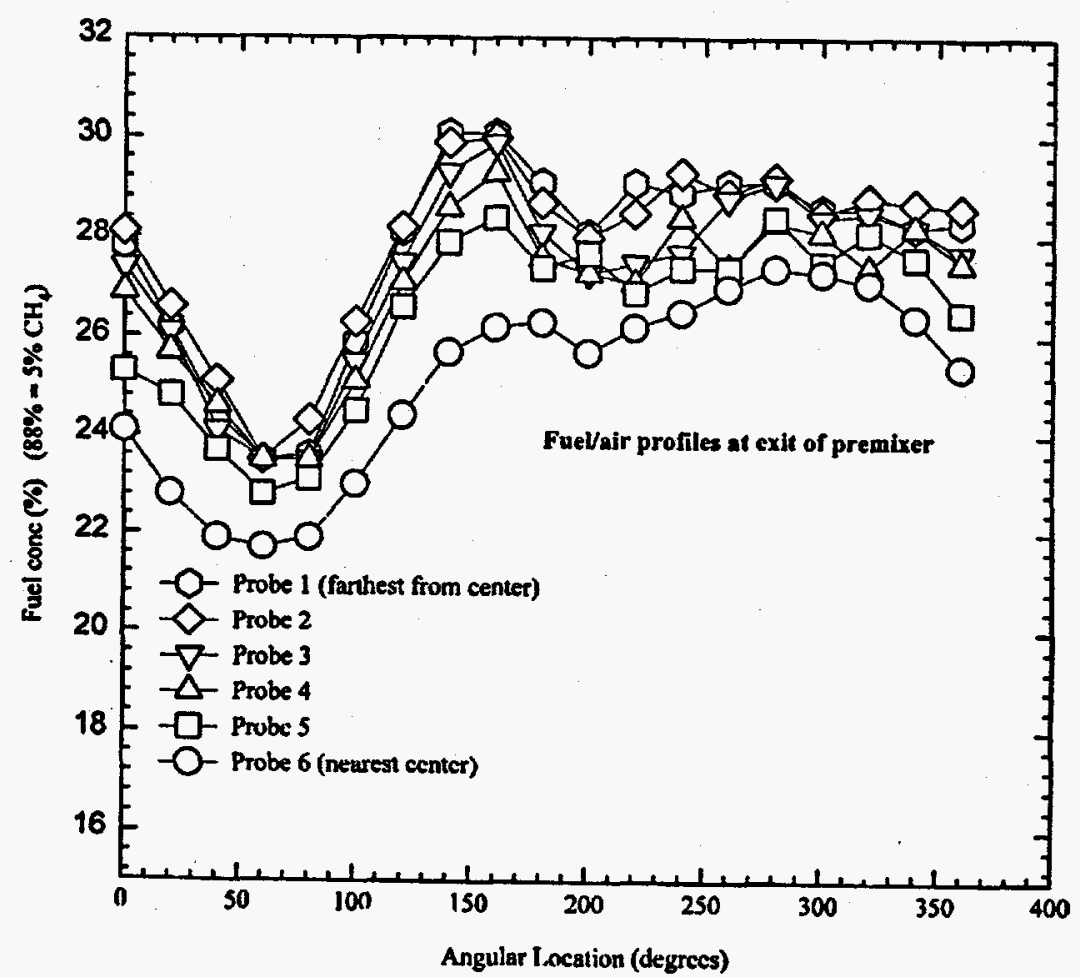

Figure 18. Premixing Measurements on Atmospheric Pressure Rig With Fuel Injectors Using Extended Spokes 
measurements under rig operating conditions. In order to accomplish this, a standard Catalytica catalyst module was modified to perform the measurements. The following changes were made to the standard catalyst module:

a) The catalyst foil was not coated with the catalyst. This allows the fuel-air ratio to be run as high as needed without any concern for catalyst overheating.

b) Small diameter tubing was fixed to the catalyst inlet with the open end pointing upstream so that multi-point fuel-air sampling could be accomplished.

c) The catalyst module consisted of all stages and components that would be used in the combustion test.

d) The sampling probes were routed through the instrumentation ports, and connected to a hydrocarbon analyzer through a multi-port valve.

The catalyst was instrumented with 33 stainless steel sampling probes. The sampling array on the blank catalyst is shown in Figure 19. Premixing measurements were conducted at a rig pressure of $120 \mathrm{psig}$ and two inlet temperatures $\left(70^{\circ} \mathrm{F}\right.$ and $\left.750^{\circ} \mathrm{F}\right)$ for the multi-venturi premixer design with the baseline fuel tubes, and fuel tubes with extended spokes. Measurements for the baseline fuel tubes at the two inlet temperatures are shown in Figures 20 and 21, while measurements for the fuel injectors with the extension spokes are shown in Figure 22. In all cases, the peak to peak variation in fuel concentrations was outside the specifications required for successful operation of the bed (>10\% peak to peak variation). Also, measurements at rig conditions showed higher non-uniformity than the mixing measurments conducted on the atmospheric pressure rig.

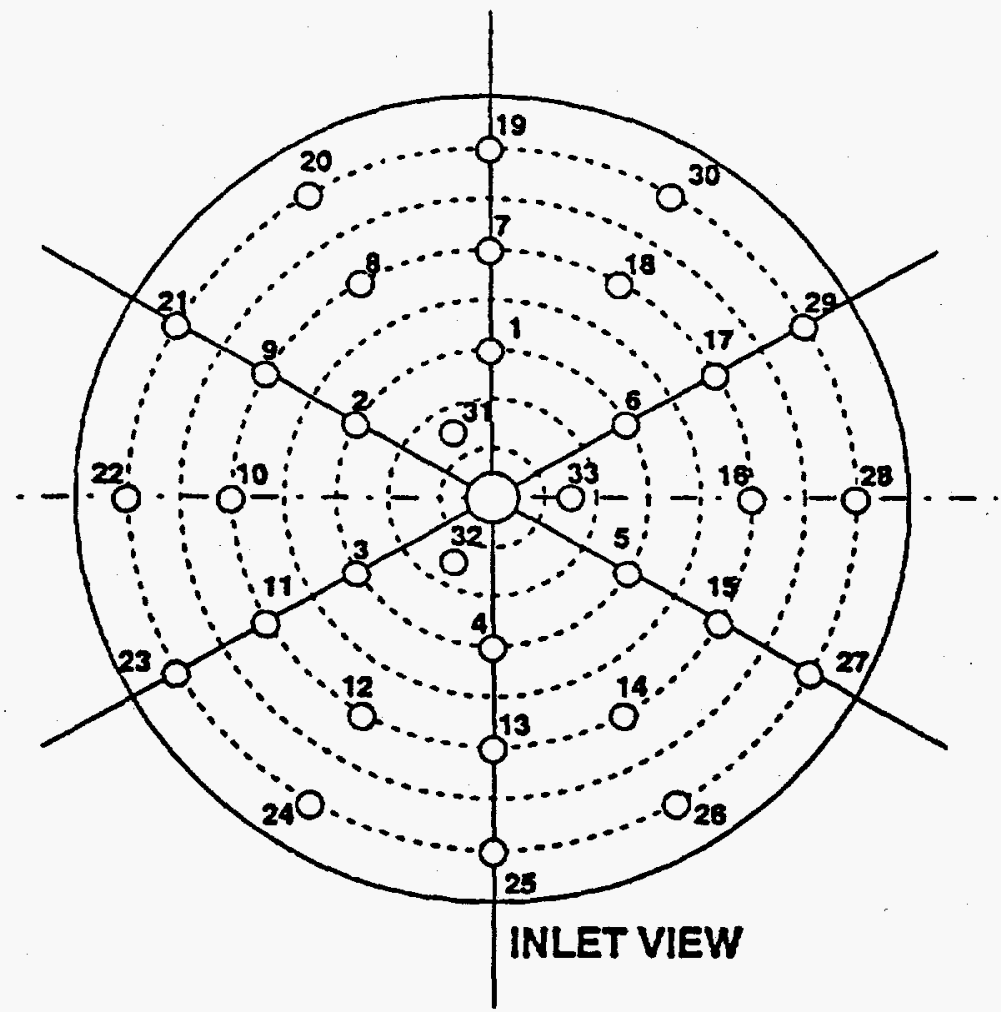

Figure 19. Arrangement of Sampling Probes on Uncoated Catalyst Module 


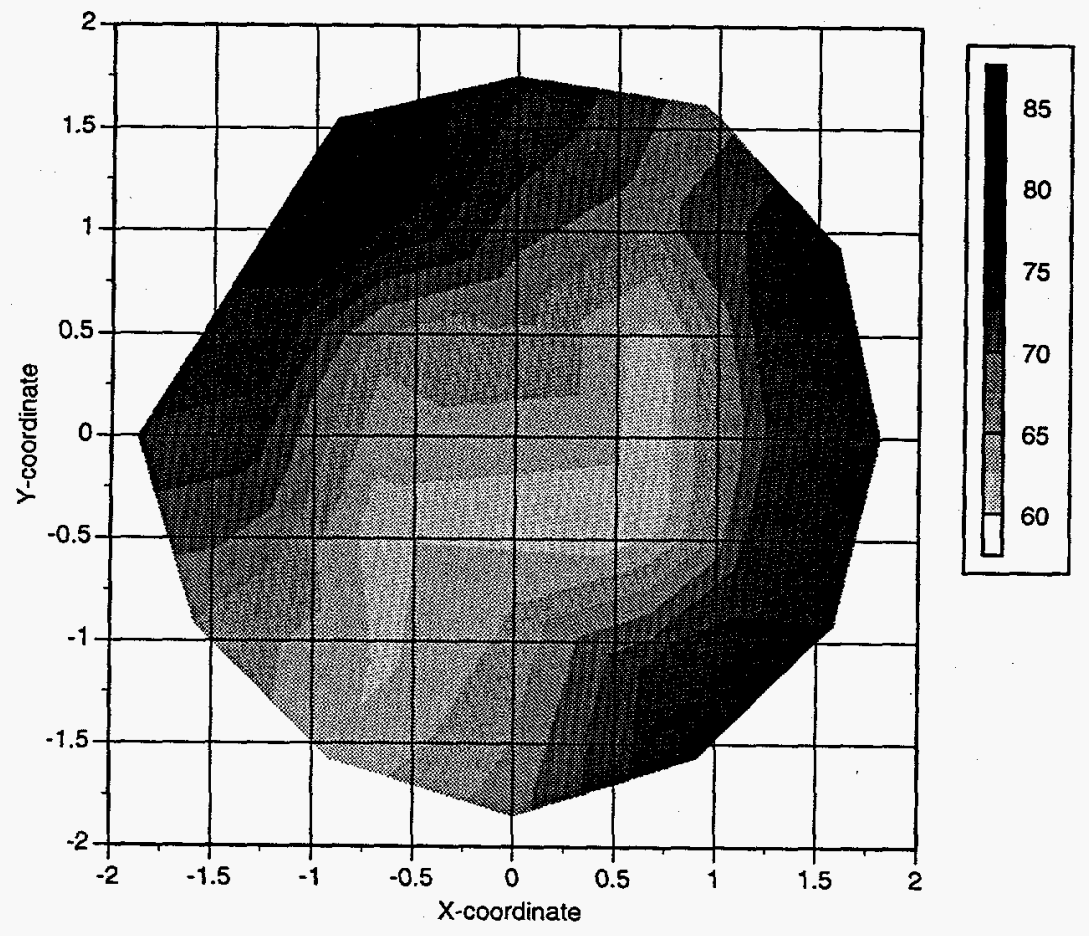

Figure 20. Premixing Measurements Under Rig Pressure and Ambient Temperature With Baseline Fuel Injectors

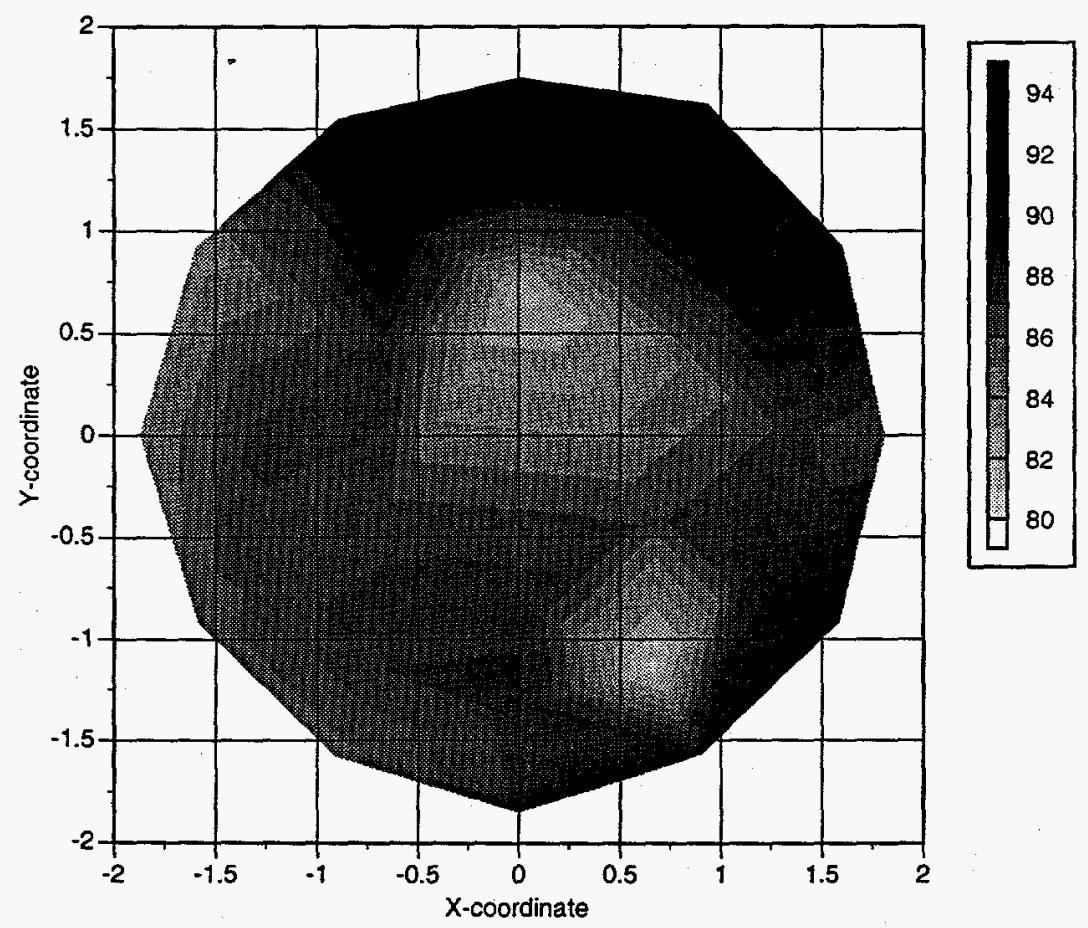

Figure 21. Premixing Measurements Under Rig Pressure and $750^{\circ} \mathrm{F}$ With Baseline Fuel Injectors 


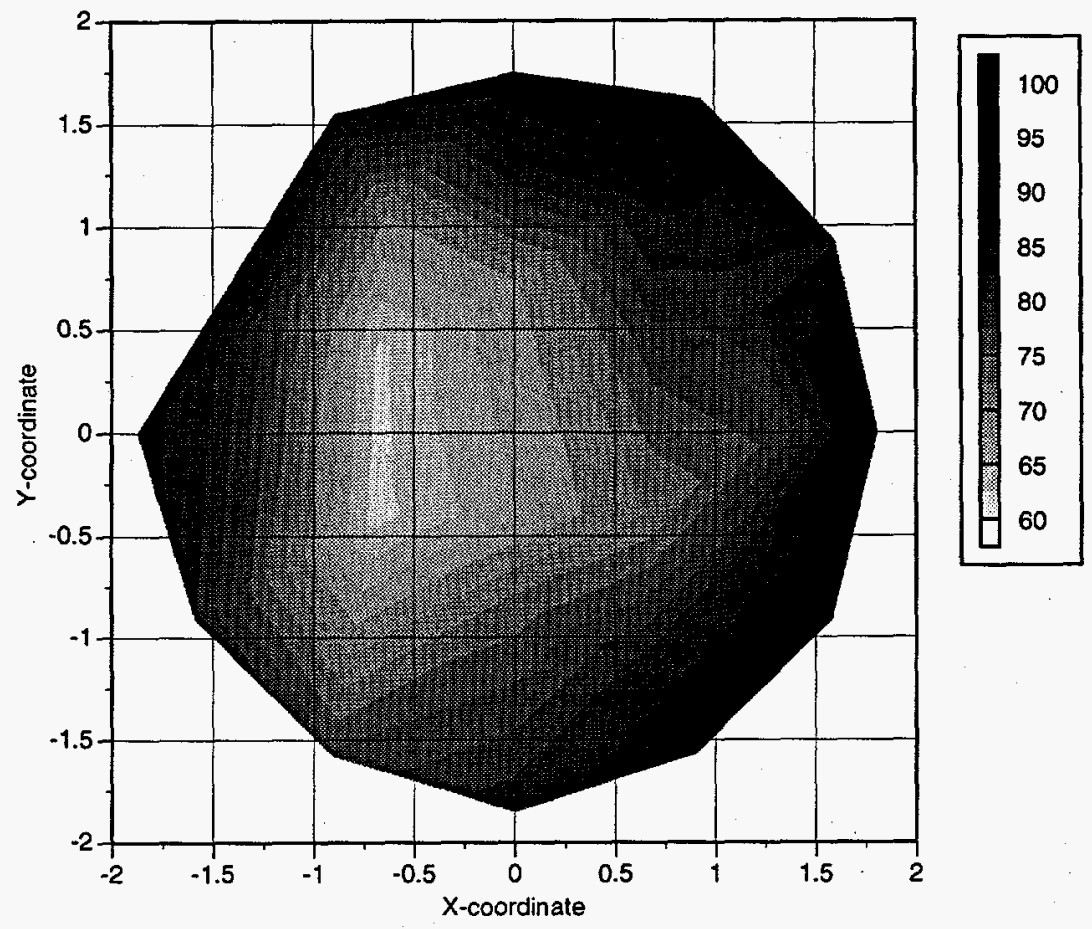

Figure 22. Premixing Measurements Under Rig Pressure and Temperature With Fuel Injectors Using Extended Spokes

In order to establish a baseline premixing level where satisfactory catalyst operation (no catalyst damage and low emissions) could be achieved, a set of five static mixers was used for the next test. Premixing measurements were conducted on the atmospheric pressure rig followed by measurements on the combustion rig with the instrumented "dummy" catalyst bed. The results from the measurements on the atmospheric pressure rig and on the combustion rig at an inlet pressure of 120 psig are shown in Figures 23 through 25. Under all conditions, the levels of premixing were well within catalyst bed specifications. Moreover, good agreement between the results at atmospheric pressure and rig conditions was obtained.

A Catalytica two-stage catalyst bed designed for the Solar Mars engine cycle was tested with the baseline premixing configuration. At full load engine conditions the test was conducted without a preburner, and the contribution of the catalyst to NOx emissions could be determined directly. Location of thermocouples at the exit of each catalyst stage are shown in Figure 26. This catalyst design did not have the 1.0 inch diameter center-body, but was a 4 inch diameter cylindrical unit with a small center plug used for catalyst fabrication. The test procedure was slightly modified to avoid the use of the auxiliany bumer downstream of the catalyst to avoid damage to the thermocouples in the homogeneous combustion zone due to locally high temperatures from the diffusion flame auxiliary burner. The catalyst module was tested over a range of fuel-air ratios and inlet gas temperatures centered around the Mars engine full load conditions. The catalyst module ignited almost immediately and very uniformly. When the stage 2 substrate temperature was near its preestablished limit, an averaged data set was recorded. Variations in stage 1 and stage 2 outlet wall, and outlet gas temperatures were typically less than $50^{\circ} \mathrm{F}$. These variations are slightly higher than the variations seen under idealized experimental conditions $\left(-25^{\circ} \mathrm{F}\right)$ on smaller catalyst beds at test facilities at Catalytica. However, they represent realistic operating conditions for engine operation. One hour of continuous steady state operation was maintained at the above conditions. Typical 


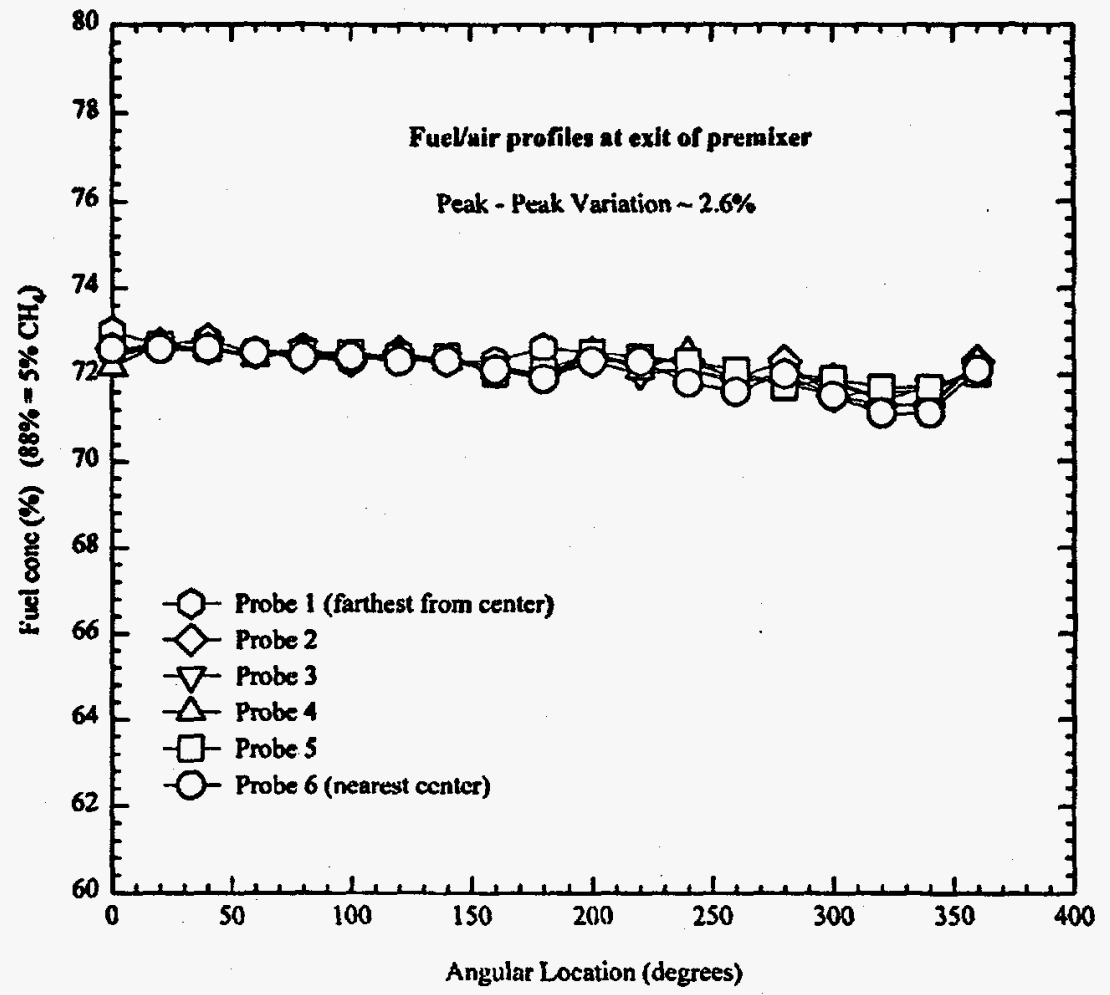

Figure 23. Premixing Measurements on Atmospheric Pressure Rig With Static Mixers
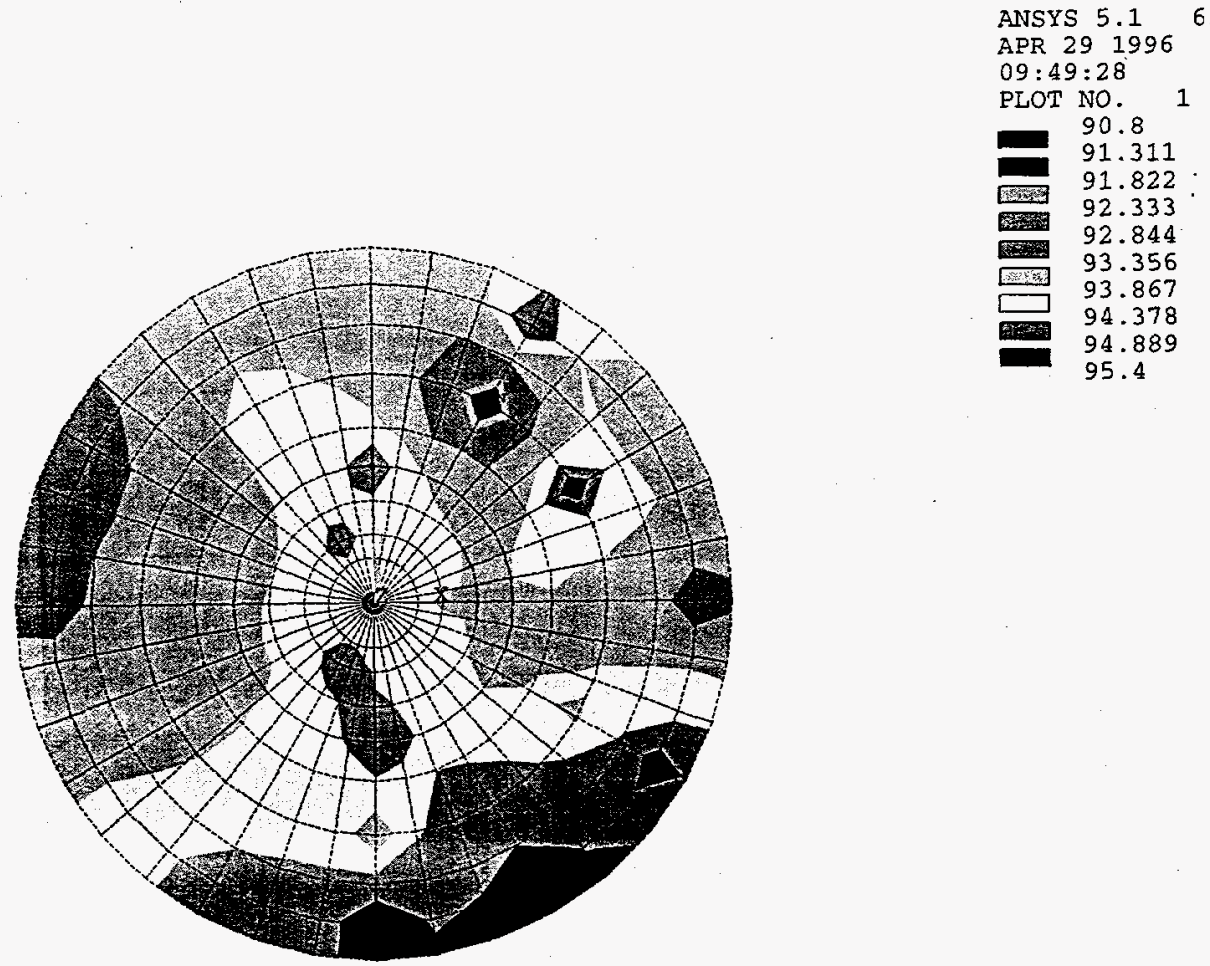

Figure 24. Premixing Measurements Under Rig Pressure and Amblent Temperature With Static Mixers 


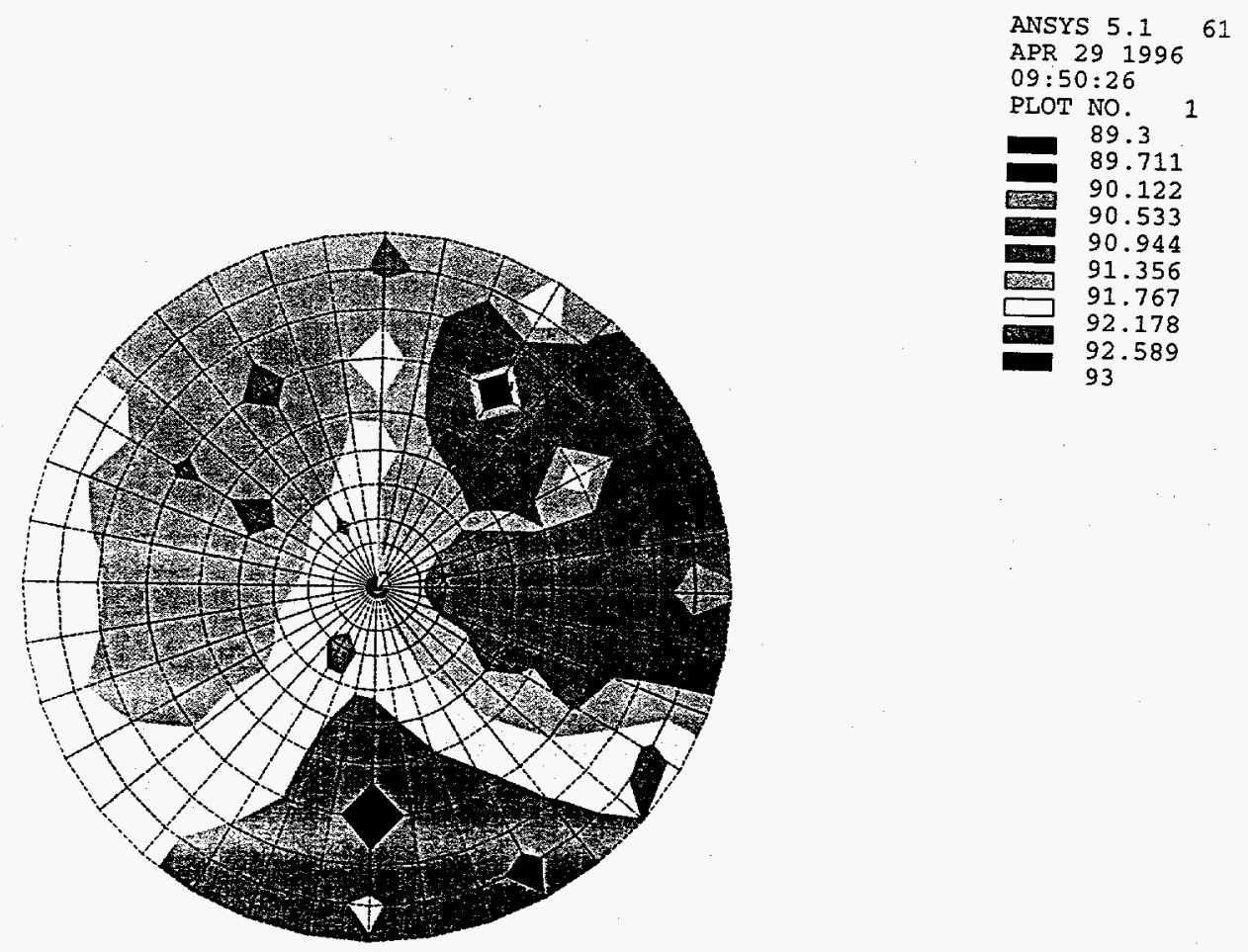

Figure 25. Premixing Measurements Under Rig Pressure and Ambient Temperature With Static Mixers

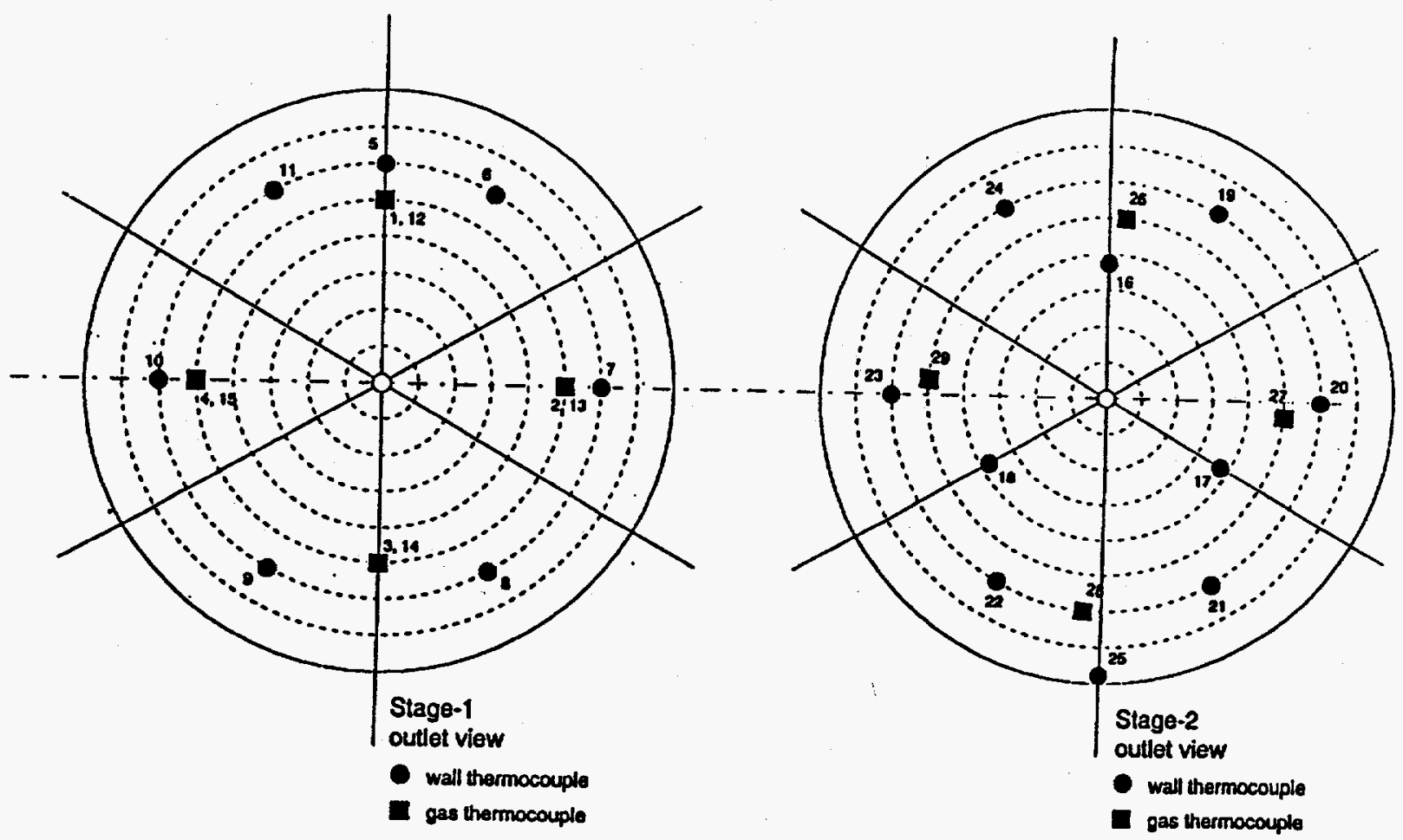

Figure 26. Location of Thermocouples on Catalyst Bed Stage 1 and Stage 2 
emissions in the range CO $<1.3 \mathrm{ppmv}$, UHC $\sim 0.0$ ppmv, NOx $<0.4 \mathrm{ppmv}$ (corrected to $15 \% \mathrm{O}_{2}$ ) were recorded. The rig conditions were then altered to reflect Mars full load conditions more closely. Data was recorded over a period of 30 mins. under steady state conditions. Emissions data over this period of catalyst operation are shown in Figure 27. The fuel flow was changed to study the effect of fuel tumdown on catalyst operation. At a F/A ratio of 0.0355 , the $\mathrm{CO}$ emissions increased beyond $10 \mathrm{ppmv}\left(@ 15 \% \mathrm{O}_{2}\right)$. With the fuel flow close to full load conditions, the inlet gas temperature was decreased to find the minimum operating temperature to maintain catalyst ignition. The inlet gas temperature was reduced in steps to $675^{\circ} \mathrm{F}$. The catalyst remained uniformly ignited and emissions were maintained below 2 ppmv $\left(@ 15 \% \mathrm{O}_{2}\right)$. Multiple light off tests were conducted under full load conditions. Every time the fuel was turned back on, the catalyst ignited, and the system returned to low emissions operation with no apparent change in performance.

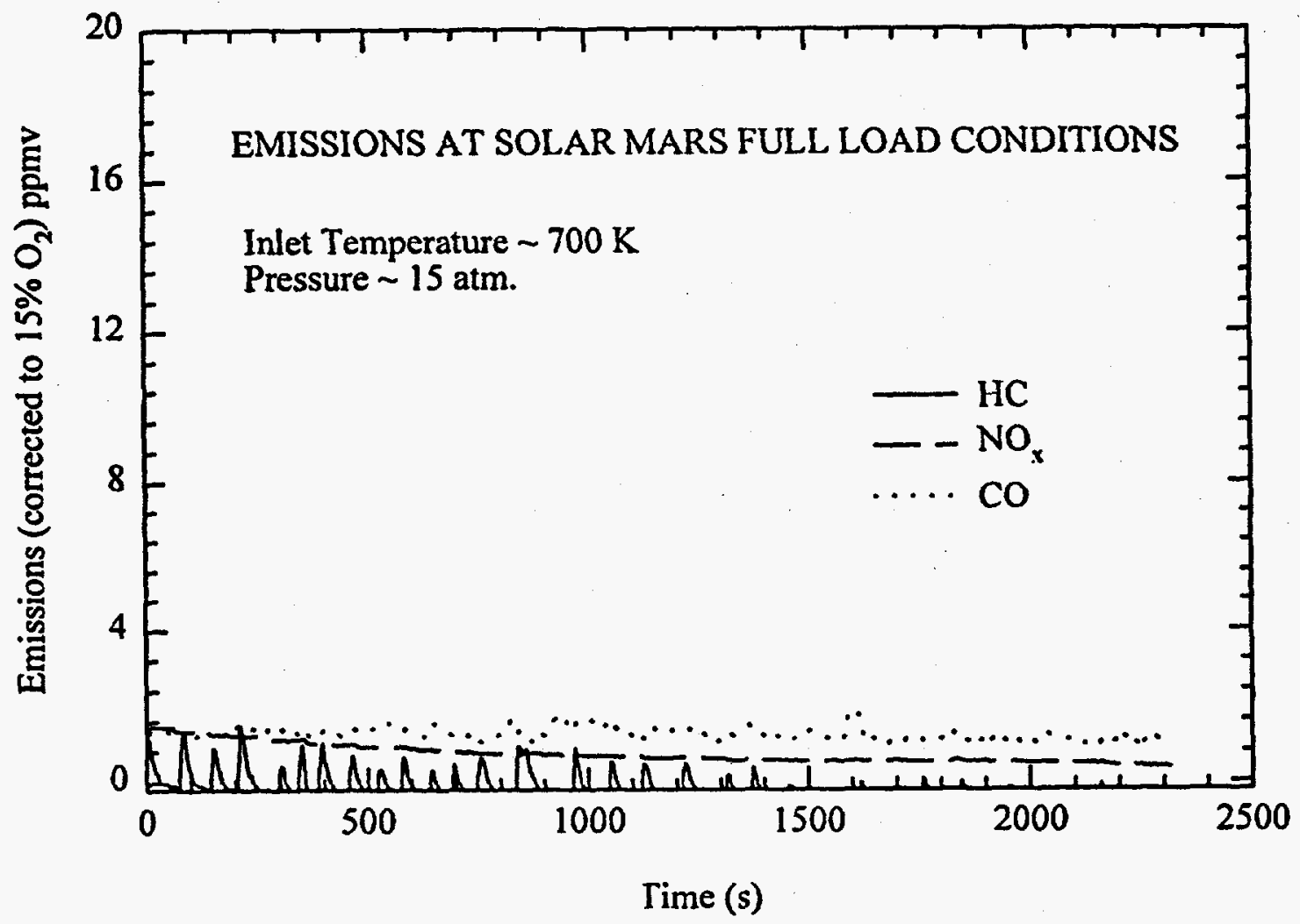

Figure 27. Emissions Measurements Under Steady State Operation at Solar Mars Full Load Conditions

This test demonstrated that high F/A non-uniformity had resulted in catalyst damage and high $\mathrm{CO}$ and UHC emissions during earlier tests. On post-test inspection, the catalyst was found to be in excellent condition, with no visible damage. No change in catalyst activity was observed in the short term tests conducted with this catalyst.

Based on the satisfactory performance of the catalyst bed at Mars design conditions, a preliminary design of a Catalytica bed. for ATS-S operating conditions was tested with the above configuration. In order to simulate full load operation, the preburner was utilized to provide an inlet temperature of $1150^{\circ} \mathrm{F}$. Catalyst operation with ultra-low emissions (< $10 \mathrm{ppmv} @ 15 \% \mathrm{O}_{2}$ ) was achieved for short periods and a typical recording of emissions data under steady state condition is shown in Figure 


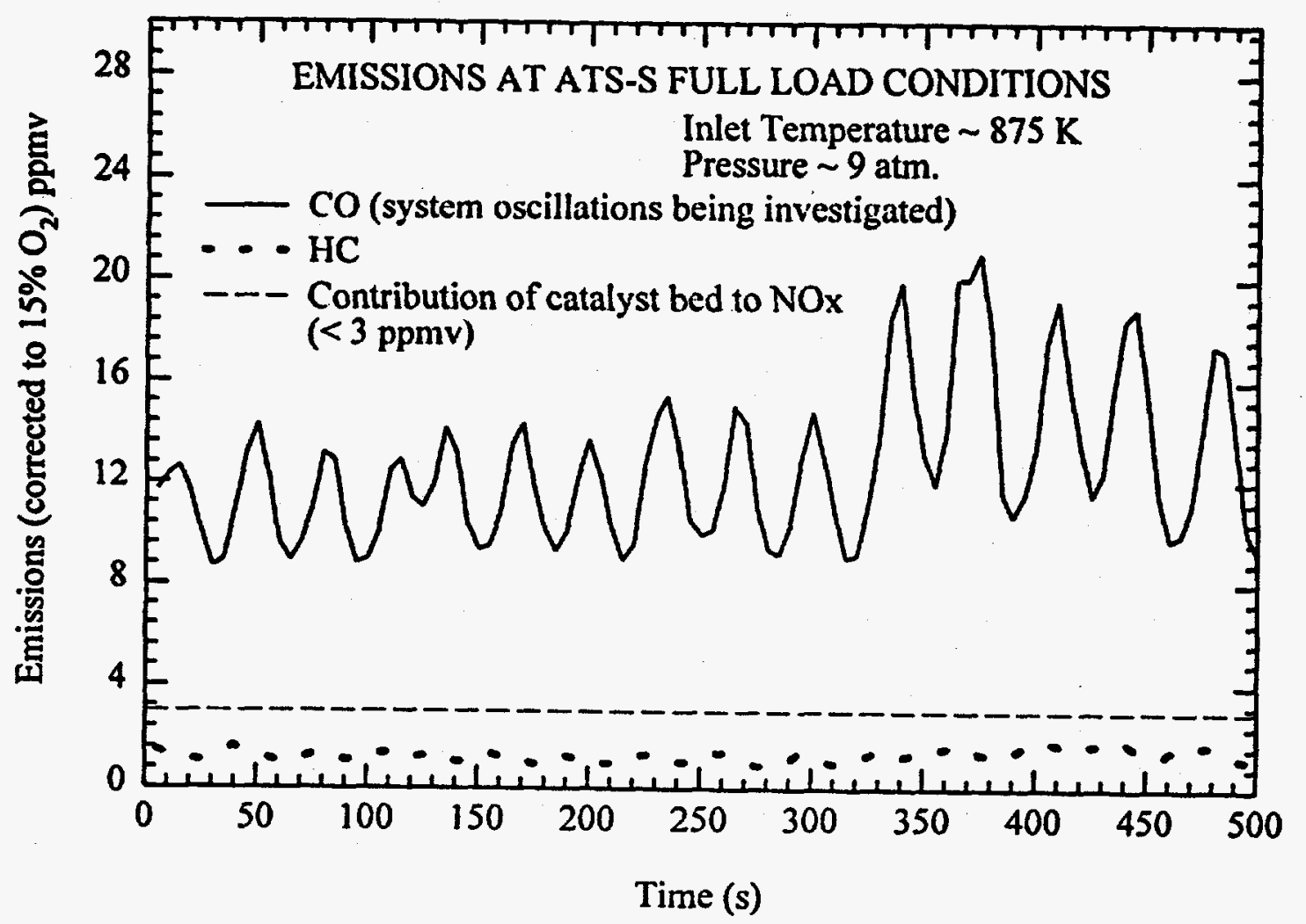

Figure 28. Emissions Measurements Under Steady State Operation at ATS-S Full Load Conditions

28. Variations in stage 1 and 2 outlet wall temperatures and outlet gas temperatures were higher than in the previous test due to variations in the inlet gas temperature with the operation of the prebumer. The increase in NOx emissions over levels produced by the preburner were typically less than 3 ppmv. UHC measurements were less than 4 ppmv (@15\% $\mathrm{O}_{2}$ ), while the CO levels tended to fluctuate between 5 and $40 \mathrm{ppmv}$ (corrected to $15 \% \mathrm{O}_{2}$ ). Low frequency oscillations of rig operational variables (e.g. air flow rates, inlet pressure) contributed to the CO concentration fluctuations due to changes in the fuel-air ratios leading to changes in the adiabatic combustion temperature. Leakage of bypass air through the ignitor torch and the auxiliary burner ports in the post catalyst combustor also contributed to periodic quenching of the $\mathrm{CO}$ oxidation reactions. Overall, the activity of the catalyst was higher than desired, and pre-determined stage 2 substrate temperatures were reached before operation at fuel-air ratios corresponding to full load design conditions could be achieved. As a result, the adiabatic combustion temperature at the steady state operating condition was barely sufficient for rapid $\mathrm{CO}$ reduction in the residence time available, and small excursions in fuel-air ratio caused significant fluctuations in the measured $\mathrm{CO}$. The catalyst design will be optimized to reduce the activity of stage 2 so that operation at fuel-air ratios corresponding to higher adiabatic temperatures is possible, and steady levels of low $\mathrm{CO}$ emissions (similar to the previous test) are obtained. Post catalyst inspection revealed the catalyst to be in good condition, and the catalyst was used in a later test.

As part of Solar's efforts to investigate alternate premixer designs, a reverse flow mixing device was evaluated among other options. A schematic of the premixer arrangement is shown in Figure 29. Fuel is injected at multiple points using fuel tubes with multiple orifices. Mixing measurements conducted on the atmospheric pressure rig, as well as using the "dummy" catalyst are shown in Figures 30 and 31 . The premixing achieved is within the specifications for the catalyst bed 


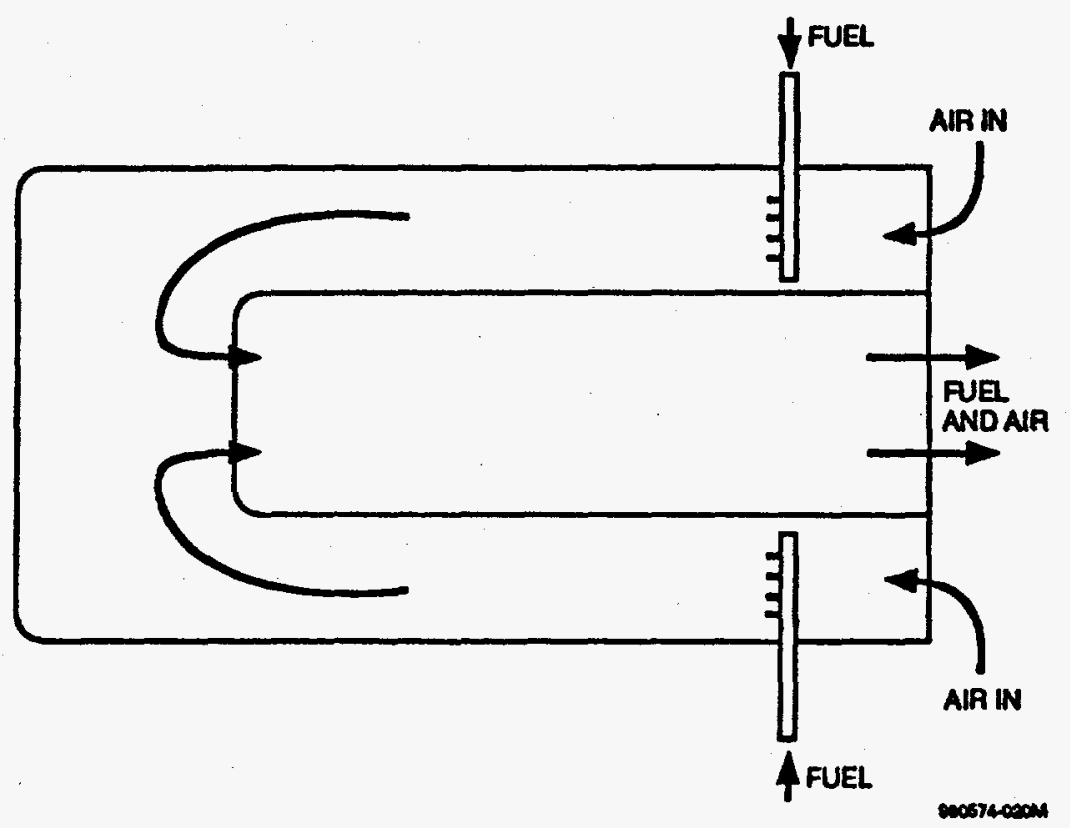

Figure 29. Schematic of Reverse Flow Premixer

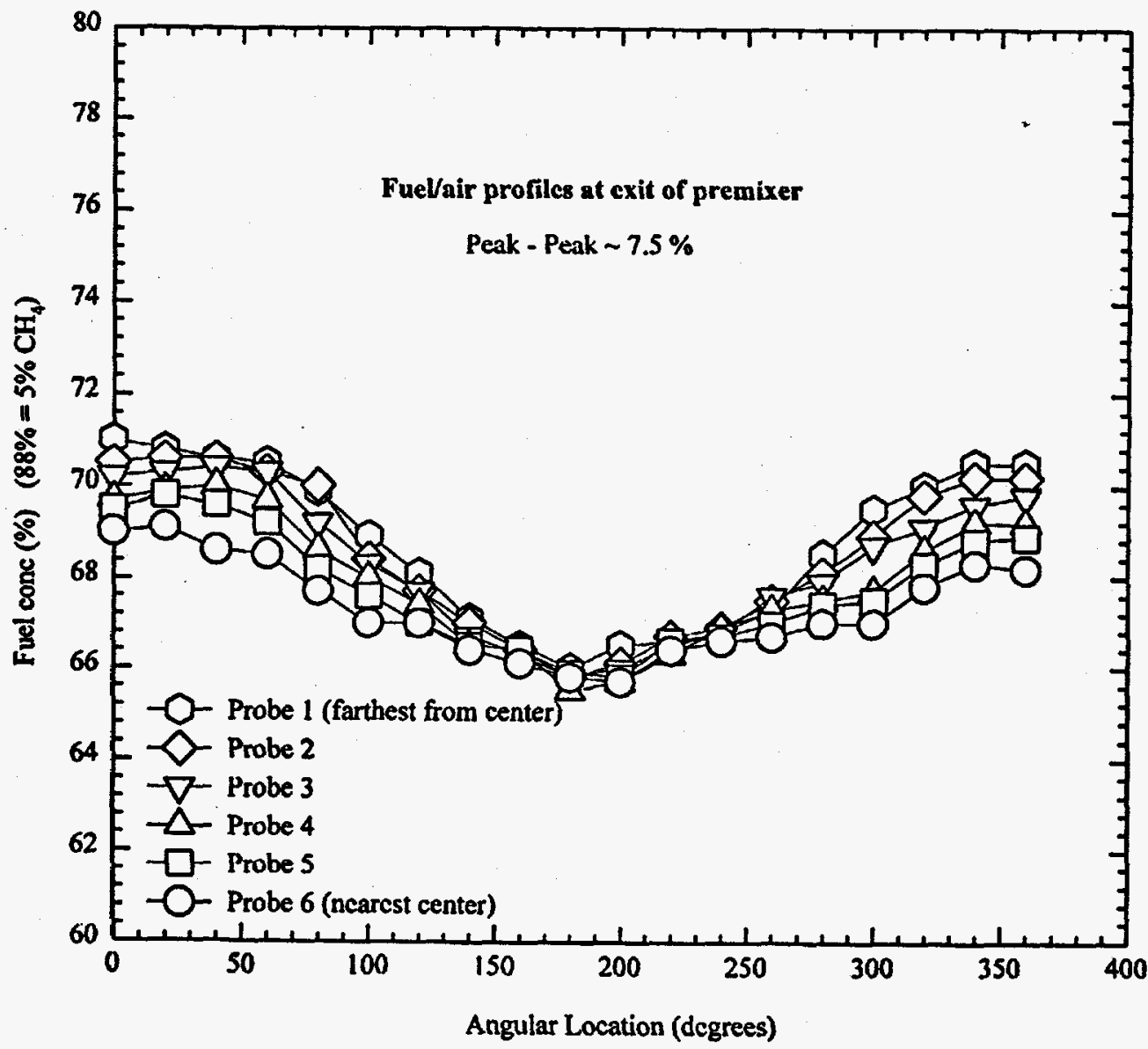

Figure 30. Premixing Measurements on Atmospheric Pressure Rig With Reverse Flow Premixer 

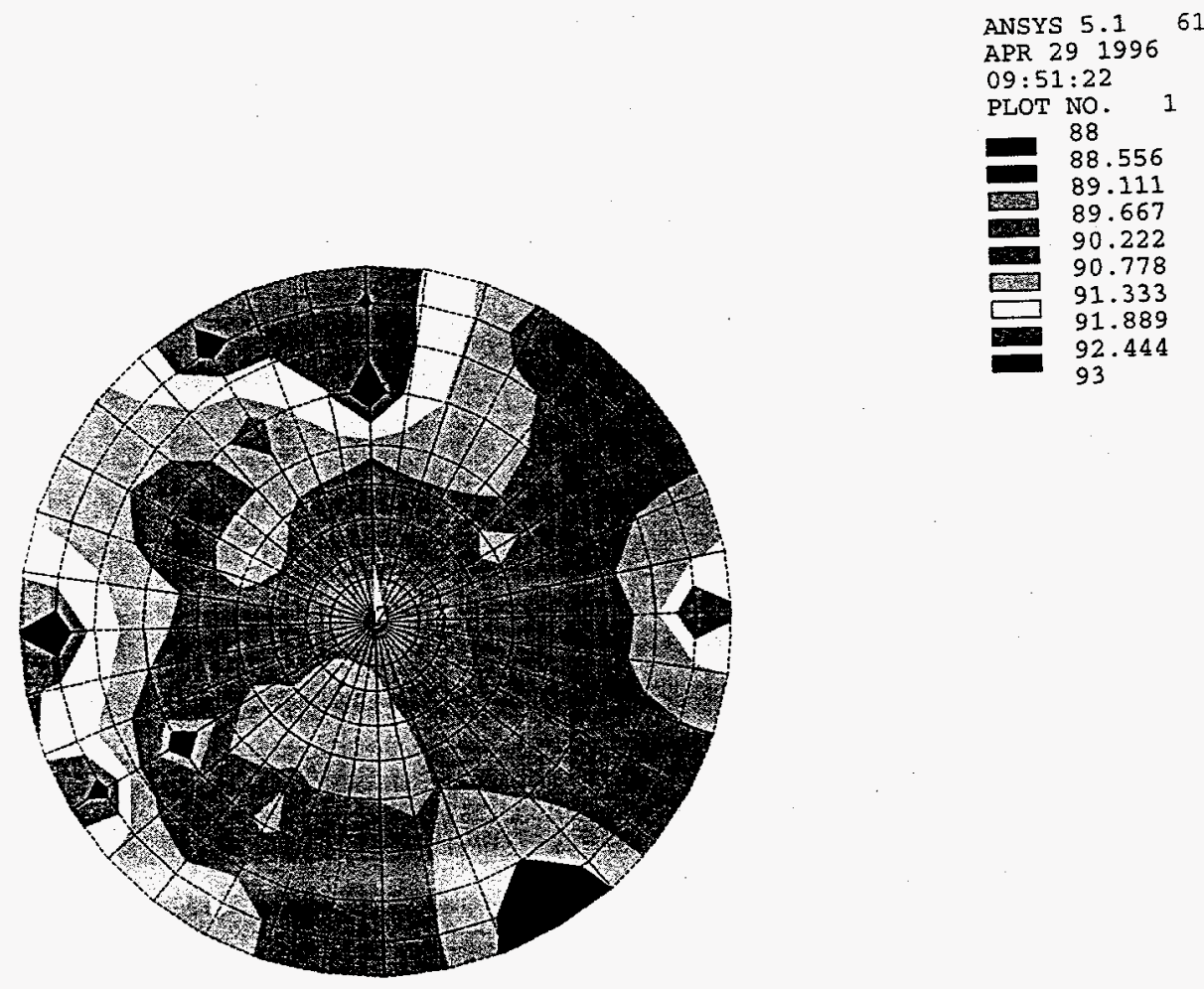

Figure 31. Premixing Measurements Under Rig Pressure and Temperature With Reverse Flow Premixer

(maximum peak to peak variation $-7 \%$ ). Once again, the atmospheric $p$ ressure measurements agree well with the measurements at elevated pressure. It is conjectured that the high levels of premixing are due to secondary flows associated with flow impingement at the wall and with centrifugal forces induced by the $180^{\circ}$ bend in the premixer.

The catalyst bed used in the previous test was tested with the reverse flow mixing configuration. Since operation of the auxiliary burner was no longer a part of the test procedure, it was decided to eliminate potential areas of air leakage into the post catalyst zone through the torch ignitor and the auxiliary bumer by shutting off the ignitor and bumer ports. Tests were conducted at simulated ATS$S$ full load conditions, and unlike the previous test, no rig oscillations were observed. Ultra-low levels of $\mathrm{CO}$ and UHC were measured along with NOx emissions levels less than 3 ppmv from the catalyst bed. Measurements over a short period of catalyst operation are shown in Figure 32. As mentioned earlier, the higher than desired activity of stage 2 once again prevented tests at fuel-air ratios corresponding to adiabatic combustion temperatures greater than $2100^{\circ} \mathrm{F}$. The effect of minimizing leakage of bypass air into the post catalyst zone was found to reduce $C O$ emissions from the previous test. Future optimization of the catalyst bed will concentrate on reducing activity in the catalyst second stage in order to have higher combustion temperatures downstream of the catalyst bed. A subscale bed design incorporating these changes will be evaluated in the subscale test rig before being tested in the full scale rig. 


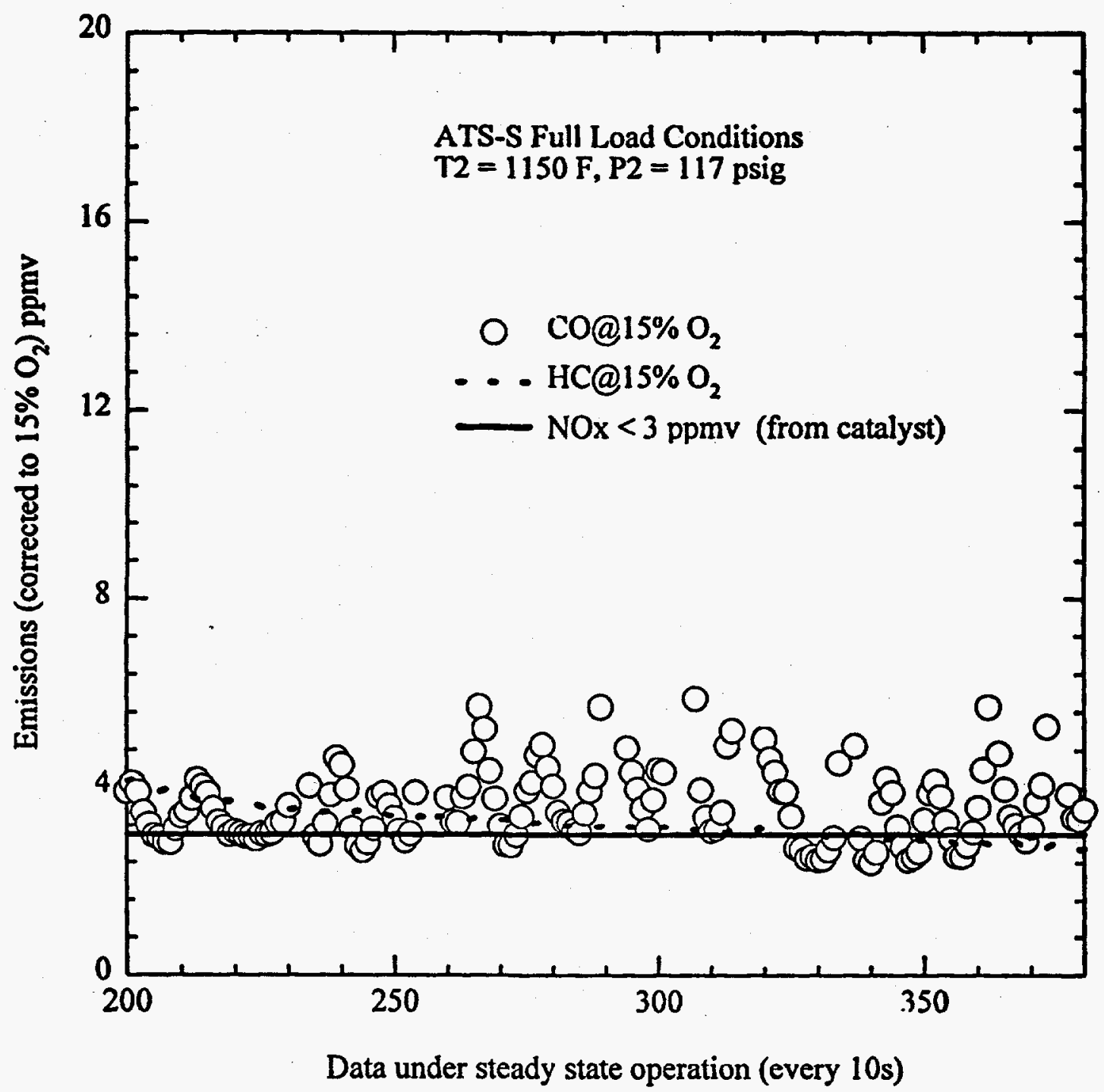

Figiure 32. Emissions Measurements Under Steady State Operation at ATS-S Full Load Conditions With Reverse Flow Premixer 


\subsection{SUMMARY, CONCLUSIONS, FUTURE WORK}

The subscale tests successfully demonstrated low emissions (NOx, CO and UHC less than 10 ppmv) using catalytic combustion at simulated Solar ATS gas turbine conditions. Some of the important results are summarized below:

1. For all test conditions, the contribution of the catalyst to NOx measurements was consistently less than 3 ppmv.

2. The subscale tests demonstrated the need for high levels of fuel-air mixedness at the catalyst bed inlet. Inhomogeneities in fuel concentartion (>10\% peak to peak variation) can lead to catalyst damage and high $\mathrm{CO}$ and UHC emissions.

3. For Solar's ATS gas turbine cycle conditions, the combustor inlet temperature at loads higher than $50 \%$ should be sufficient to allow catalyst ignition without a prebumer, and ultra-low NOx operation should be obtainable across the 50 to $100 \%$ load range. This may not be the case for many simple cycle gas turbines.

4. Limited F/A turndown of the catalyst will require air staging through variable geometry to maintain ultra-low CO emissions over the 50 to $100 \%$ load range.

5. The design of the post-catalyst homogeneous combustion region is critical for obtaining low $\mathrm{CO}$ emissions.

6. Several premixer designs were evaluated during the subscale tests, and some designs were found to provide fuel-air mixing meeting the specifications for the catalyst bed. Additional work will be required to scale-up subscale designs for use in the full scale test rig.

7. In short term testing, the catalysts showed the desired chemical activity, and no observable change in performance between tests. Multiple light off sequences were routinely performed, without any detrimental effects on the catalyst.

The subscale test results have provided a technical basis for the design and fabrication of a single can full scale combustor that is representative of a multi-can catalytic combustion system. While the subscale tests concentrated primarily on the catalytic reactor, the full scale tests involve the integration of the three main catalytic combustor modules (premixer with variable geometry, catalyst bed, post-catalyst combustor) to provide the framework for future implementation of catalytic combustion in an ATS gas turbine. 


\subsection{REFERENCES}

Anderson, D. N., Tacina, R. R., and Mroz, T. S., 1975, "Performance of a Catalytic Reactor at Simulated Gas Turbine Combustor Operating Conditions," NASA TM-X-71747.

Beebe, K. W., Cutrone, M. B., Matthews, R. N., Dalla Betta, R. A., Schlatter, J. C., Furuse, Y., and Tsuchiya, T., 1995a, "Design and Test of a Catalytic Combustor for a Heavy Duty Industrial Gas Turbine," ASME 95-GT-137.

Beebe, K. W., Cutrone, M. B., Dalla Betta, R. A., Schlatter, J. C., Nikolas, S., Furuse, Y., and Tsuchiya, T., 1995b, "Development of a Catalytic Combustor for a Heavy Duty Utility Gas Turbine," Proceedings of the Yokohama International Gas Turbine Conference, October 22-26, Yokohama, Japan.

Correa, S. M., 1992, "A Review of NO Formation Under Gas-Turbine Combustion Conditions," Combustion Science and Technology, Vol. 87, pp. 329-362.

Dalla Betta, R. A., Schlatter, J. C., Nickolas, S. G., Lodewykx, A., Shoji, T., and Sasaki, M., 1993, "New Catalytic Combustion Technology for very Low Emissions Gas Turbines," EPRI and EPA Joint Symposium on Stationary Combustion NOx Control, Miami Beach, Florida.

Dalla Betta, R. A., Schlatter, J. C., Nickolas, S. G., Razdan, M. K., and Smith, D. A., 1995, "Application of Catalytic Combustion Technology to Industrial Gas Turbines for Ultra-Low NOX Emissions," ASME 95-GT-65.

Kolaczkowski, S. T., 1995, "Catalytic Stationary Gas Turbine Combustors: A Review of the Challenges Faced to Clear the Next Set of Hurdles," Trans. IChemE, Vol. 73, Part A.

Matthews, R. D. and Sawyer, R. F., 1977, "Fuel Nitrogen Conversion and Catalytic Combustion," Proceedings of the Western States Section of the Combustion Institute, Paper No. 77-40, Palo Alto, CA.

Nicol, D. G., Steele, R. C., Marinov, N. M., and Malte, P. C., 1995, "The Importance of the Nitrous Oxide Pathway to NOx in Lean-Premixed Combustion," ASME Journal of Engineering for Gas Turbines and Power, Vol. 114, No. 1, pp. 100-111.

Pfefferle, W. C., 1975, "Catalytically Supported Thermal Combustion," U.S. Patent 3,928,961.

Pfefferle, W. C., 1986, "Catalytically Stabilized Combustion," Progress in Energy and Combustion Science, Vol. 12, pp. 25-41.

Rawlins, D. C., 1995, "Dry Low Emissions: Improvements to the SoLoNOx Combustion System," Eleventh Symposium on Industrial Applications of Gas Turbines, Canadian Gas Association, October 11-13, Banff, Alberta, Canada.

Tacina, R. R., 1977, "Experimental Evaluation of Fuel Preparation Systems for an Automotive Gas Turbine Catalytic Converter," NASA TM-78856.

Weinberg, F. J., 1986, Advanced Combustion Methods, Academic Press. 